Document downloaded from:

http://hdl.handle.net/10251/105545

This paper must be cited as:

Fernández Domene, RM.; Sánchez Tovar, R.; Lucas-Granados, B.; Roselló-Márquez, G.; Garcia-Anton, J. (2017). A simple method to fabricate high-performance nanostructured WO3 photocatalysts with adjusted morphology in the presence of complexing agents. Materials \& Design. 116:160-170. doi:10.1016/j.matdes.2016.12.016

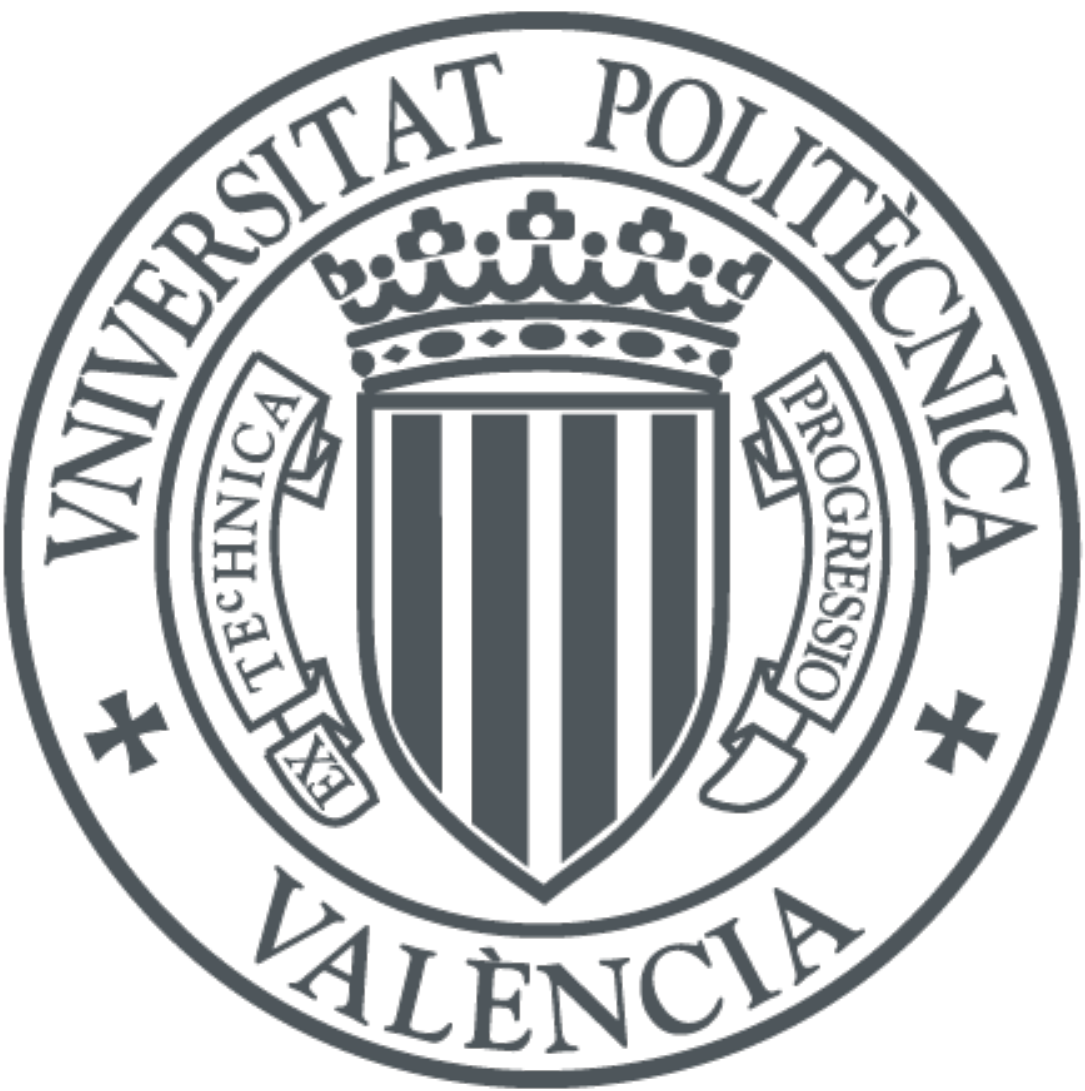

The final publication is available at

http://doi.org/10.1016/j.matdes.2016.12.016

Copyright Elsevier

Additional Information 


\title{
A SIMPLE METHOD TO FABRICATE HIGH-PERFORMANCE NANOSTRUCTURED WO 3 PHOTOCATALYSTS WITH ADJUSTED MORPHOLOGY IN THE PRESENCE OF COMPLEXING AGENTS
}

\author{
Fernández-Domene, R.M.; Sánchez-Tovar, R.; Lucas-Granados, B. ; Roselló- \\ Márquez, G.; García-Antón, J. \\ Ingeniería Electroquímica y Corrosión (IEC). Departamento de Ingeniería Química y \\ Nuclear. ETSI Industriales. Universitat Politècnica de València. Camino de Vera s/n, \\ 46022 Valencia, Spain. Tel. 34-96-387 76 32, e-mail: jgarciaa@iqn.upv.es (J. García- \\ Antón); raferdo1@etsii.upv.es (R.M. Fernández-Domene).
}

The rich and complex chemistry of tungsten was employed to synthesize innovative $\mathrm{WO}_{3}$ nanoplatelets/nanosheets by simple anodization in acidic electrolytes containing different concentrations of complexing agents or ligands, namely $\mathrm{F}^{-}$and $\mathrm{H}_{2} \mathrm{O}_{2}$. The morphological and photoelectrochemical properties of these nanostructures were characterized. The best of these nanostructures generated stable photocurrent densities of ca. $1.8 \mathrm{~mA} \mathrm{~cm}^{-2}$ at relatively low bias potentials (for $\mathrm{WO}_{3}$ ) of $0.7 \mathrm{~V}_{\mathrm{Ag} / \mathrm{AgCl}}$ under simulated solar irradiation, which can be attributed to a very high active surface area. This work demonstrates that the morphology and dimensions of these nanostructures, as well as their photoelectrochemical behavior, can be controlled by adjusting the ligand concentration in the electrolytes, hence providing an easy and non-expensive route to fabricate and customize high-performance nanostructured photocatalysts for clean energy production and environmental applications.

KEYWORDS: $\mathrm{WO}_{3}$ nanostructures, synthesis, anodization, complexing agents, hydrogen peroxide, photocatalysis. 


\section{Introduction}

Tungsten trioxide $\left(\mathrm{WO}_{3}\right)$ is an $n$-type semiconductor oxide which has been studied in detail due to its attractive optical, electrical and photocatalytic properties. In particular, $\mathrm{WO}_{3}$ is an attractive photoanode material owing to its high electron mobility, moderate hole diffusion length $(\approx 150 \mathrm{~nm})$ and non-toxicity. Besides, $\mathrm{WO}_{3}$ can also absorb a part of the visible rays of the solar spectrum (its band-gap is $E_{g} \approx 2.6 \mathrm{eV}$, which corresponds approximately to a wavelength of $\sim 480 \mathrm{~nm}$ ) [1-4]. Tungsten trioxide has been employed in technologically advanced fields, such as photoelectrochemistry and photodegradation of organic pollutants [4-14], dye-sensitized solar cells [15], gas sensors [16] or electrochromic devices [17-19].

The design and fabrication of semiconductor oxides in nanostructured form for their use as photoelectrocatalysts is a novel and growing discipline of materials chemistry. Nanostructured electrodes can drastically increase the efficiency of photoelectrochemical processes, due to their higher specific surface area (which enhances the charge transfer kinetics at the photoelectrode/electrolyte interface), to the shorter diffusion path lengths for the photogenerated charge carriers, and to the existence of quantum size effects [20]. $\mathrm{WO}_{3}$ nanostructures (nanopores, nanorods/nanowires, nanoplatelets, etc.) have been synthesized by a number of different techniques such as hydrothermal methods [3, 12, 21], solvothermal methods [22, 23], sol-gel [24, 25], deposition processes (laser deposition [17], electrodeposition [1, 2632], chemical vapor deposition [33], atomic layer deposition [14], RF sputtering [34], spin coating [35]), dry chemistry methods (plasma-assisted approach [36]) and anodization [1, 6, 7, 15, 37]. 
It is known that the chemistry of aqueous tungsten solutions is complex, since a wide variety of species can be obtained depending on many factors, such as the composition, the $\mathrm{pH}$ or the temperature of the solutions [38]. The formation of condensed isopolytungstates in acidic solutions and, especially, the interaction of $\mathrm{WO}_{3}$ with ligands or complexing agents (such as fluoride, hydrogen peroxide or polycarboxylic acids) can be used to customize $\mathrm{WO}_{3}$ nanostructures, thus providing a wide range of possibilities to obtain new morphologies and improved properties. Although the chemistry of tungsten species is incompletely understood, there is increasing interest in tungsten (VI) complexation for the fabrication of $\mathrm{WO}_{3}$ nanostructures [1, 6, 8, 9, 23, 28-32, 39-45]. However, little work concerning the synthesis of $\mathrm{WO}_{3}$ nanostructures by anodization in solutions containing complexing agents has been developed, and most of these studies deal with tungsten anodization in the presence of fluoride anions [6, 8, 9, 39, 40, 45]. Concentrated $\mathrm{H}_{2} \mathrm{O}_{2}$-containing electrolytes (20-30 \%) have been used to dissolve tungsten powders as a first step to obtain tungsten solutions which will act subsequently as precursors in the formation of $\mathrm{WO}_{3}$ nanostructures, mainly using electrodeposition techniques [29-32]. However, by using anodization in the presence of very low concentrations of $\mathrm{H}_{2} \mathrm{O}_{2}$ (lower than $0.5 \%$ ), formation of $\mathrm{WO}_{3}$ nanostructures could be achieved in a simple and non-expensive single step, instead of using several stages involving different degrees of complexity and high amounts of $\mathrm{H}_{2} \mathrm{O}_{2}$. To our knowledge, the formation of $\mathrm{WO}_{3}$ nanostructures by anodization of tungsten in the presence of $\mathrm{H}_{2} \mathrm{O}_{2}$ has not been reported. Therefore, the aim of this work is to develop new $\mathrm{WO}_{3}$ nanostructures by anodization of tungsten in the presence of different ligands, namely, fluoride and especially hydrogen peroxide. The influence of the ligand concentration on the morphology, composition and photoelectrochemical behavior of 
the formed nanostructures has been investigated through Field Emission Scanning Electron Microscopy (FESEM), Confocal Raman Microscopy and electrochemical and photoelectrochemical measurements.

\section{Experimental procedure}

Tungsten rods of $8 \mathrm{~mm}$ in diameter were used as working electrodes in the anodization process. Before anodization, the samples were wet abraded with SiC papers, from 220 to 4000 grit, ultrasonicated in ethanol for 2 minutes, rinsed with deonized water and finally dried in an air stream. The abraded and cleaned tungsten cylinders were tefloncoated (to expose an area of $0.5 \mathrm{~cm}^{2}$ to the electrolyte) and immersed in the anodization cell, where a platinum mesh acted as a counter electrode.

All anodization tests were carried out for $4 \mathrm{~h}$ applying a cell potential of $20 \mathrm{~V}$, at a temperature of $50{ }^{\circ} \mathrm{C}$ and at a rotation velocity (using a rotating disk electrode, RDE) of $375 \mathrm{rpm}$. These values were chosen according to a previous work [6]. Anodization electrolytes consisted of solutions of complexing agents or ligands in several concentrations: fluoride anions (prepared from $\mathrm{NaF}$ in the range 0-0.25 $\mathrm{M}$ ) and hydrogen peroxide (in the range 0-0.2 M). The solutions also contained $1.5 \mathrm{M} \mathrm{H}_{2} \mathrm{SO}_{4}$ to achieve an acidic $\mathrm{pH}$ and to favor polycondensation of tungsten species. The electrolyte without complexing species (only sulfuric acid) has been labeled in the results as “blank”. After anodization, the samples were annealed at $400{ }^{\circ} \mathrm{C}$ for $4 \mathrm{~h}$ in a cylindrical oven in the presence of oxygen. 
The morphology of the obtained nanostructures was observed by a Field Emission Scanning Electron Microscopy (FESEM). Raman spectroscopy (Witec alpha300 R Confocal Raman Microscope) was used to determine the composition and the crystalline phase of the nanostructures.

Finally, photoelectrochemical measurements were performed using an Autolab PGSTAT302N potentiostat and a solar simulator (AM 1.5 conditions at $100 \mathrm{~mW} \mathrm{~cm}^{-2}$ ). The photoelectrochemical cell consisted of an $\mathrm{Ag} / \mathrm{AgCl}(3 \mathrm{M} \mathrm{KCl})$ reference electrode, a platinum tip counter electrode, and the nanostructures as a working electrode, with an area of $0.13 \mathrm{~cm}^{2}$ exposed to the electrolyte ( $5 \mathrm{M} \mathrm{LiCl}$ with $65 \mathrm{~mol} \%$ methanol, $\mathrm{pH} 0$, to assure the photostability of the samples [6]). Photocurrent density vs. potential plots were obtained scanning the potential from $-0.24 \mathrm{~V}_{\mathrm{Ag} / \mathrm{AgCl}}$ to $1.02 \mathrm{~V}_{\mathrm{Ag} / \mathrm{AgCl}}$, at a scan rate of $2 \mathrm{mV} \mathrm{s}^{-1}$. The potential scan started in dark conditions and the nanostructures were illuminated every 60 seconds for 20 seconds. After the potential scan, the nanostructures were kept at $1.02 \mathrm{~V}_{\mathrm{Ag} / \mathrm{AgCl}}$ for $1 \mathrm{~h}$ under illumination to check their photostability.

\section{Results and discussion}

\subsection{Fluoride solutions}

In order to investigate the influence of fluoride concentration on the mechanism of formation of the $\mathrm{WO}_{3}$ nanostructures, current density transients were recorded during the anodization process (Figure 1). In general, three different regions can be discerned. In Region I, the sharp decrease in current density observed during the first seconds of 
anodization indicates the fast formation of a compact $\mathrm{WO}_{3}$ layer which isolated to some extent the tungsten surface:

$$
\mathrm{W}+3 \mathrm{H}_{2} \mathrm{O} \rightarrow \mathrm{WO}_{3}+6 \mathrm{H}^{+}+6 \mathrm{e}^{-}
$$

In the absence of fluorides, this layer was subsequently dissolved by the action of protons [46, 47]:

$$
\mathrm{WO}_{3}+2 \mathrm{H}^{+} \rightarrow \mathrm{WO}_{2}^{2+}+\mathrm{H}_{2} \mathrm{O}
$$

which resulted in an increase in current density (Region II, Figure 1) as tungsten fresh surface was again exposed to the electrolyte. During this dissolution, soluble cationic species $\left(\mathrm{WO}_{2}{ }^{2+}\right.$ or $\left[\mathrm{W}(\mathrm{OH})_{4}\left(\mathrm{H}_{2} \mathrm{O}\right)_{4}\right]^{2+}$ in its hydrated form) were released to the electrolyte. At $\mathrm{pH}<1$ and under the presence of the high electric field at the interface between the tungsten oxide and the electrolyte interface, electrochemical dissolution of the tungsten substrate through the oxide could also occur, according to [46]:

$$
\mathrm{W}+2 \mathrm{H}_{2} \mathrm{O} \rightarrow \mathrm{WO}_{2}^{2+}+4 \mathrm{H}^{+}+4 \mathrm{e}^{-}
$$

As the chemical and electrochemical dissolution of the $\mathrm{WO}_{3}$ layer proceeded, increasing amounts of tungsten cationic species were formed. It can be assumed that cationic tungsten entities were in equilibrium with anionic tungstates $\left(\mathrm{WO}_{4}{ }^{2-}\right.$ or $\left[\mathrm{W}(\mathrm{OH})_{8}\right]^{2-}$ in its hydrated version), although their concentration was low due to the electrolyte acidic $\mathrm{pH}$. These species reacted to form polycondensed tungstates [38]: 


$$
2 \mathrm{WO}_{4}^{2-}+\mathrm{WO}_{2}^{2+} \rightarrow\left[\mathrm{O}_{3} \mathrm{~W}-\mathrm{O}-\mathrm{WO}_{2}-\mathrm{O}-\mathrm{WO}_{3}\right]^{2-}
$$

Polycondensation can also be considered as a dehydration process due to the addition of protons to tungstate ions, and at $\mathrm{pH}$ values close to 1 the $\mathrm{W}: \mathrm{H}_{2} \mathrm{O}$ ratio is $\sim 1: 2$, which corresponds to precipitated tungstic acid [38].

Hence, after certain time (when supersaturation conditions were reached), polytungstates precipitated on the electrode surface in the form of insoluble and highly polimeric tungstic acids $\left(\mathrm{WO}_{3} \cdot \mathrm{H}_{2} \mathrm{O}\right.$ and $\left.\mathrm{WO}_{3} \cdot 2 \mathrm{H}_{2} \mathrm{O}\right)$, due to the strongly acidic $\mathrm{pH}$ of the electrolyte $[38,46]$. This precipitate partially blocked the tungsten surface, which resulted in a decrease in current density (Region III, Figure 1).

In the presence of fluorides, the initial decrease in current density (Region I, Figure 1) was also observed, although $i$ values were higher than in the fluoride-free electrolyte. In Region II, current densities were also higher, increasing with fluoride concentration. Fluoride ions acted as monodentate ligands which formed stronger bonds with tungsten than those formed between tungsten and oxygen $\left(\mathrm{O}^{2-}\right.$ ions), with a coordination number up to 8. In acidic media and in the presence of fluoride anions, the $\mathrm{WO}_{3}$ layer formed in Region I underwent localized dissolution into soluble fluoride complexes:

$$
\mathrm{WO}_{3}+6 \mathrm{H}^{+}+\mathrm{nF}^{-} \rightarrow\left[\mathrm{WF}_{\mathrm{n}}\right]^{(6-\mathrm{n})}+3 \mathrm{H}_{2} \mathrm{O}
$$

Therefore, an increase in fluoride concentration resulted in a higher dissolution rate of the $\mathrm{WO}_{3}$ layer, increasing the amount of soluble complexes released to the electrolyte, and thus in higher current densities due to the oxidation of the tungsten substrate. 
In Region III (Figure 1), current density values decreased again due to the precipitation of polytungstates in the form of tungstic acids, as explained above for the $\mathrm{F}^{-}$-free electrolyte. This decrease, however, appeared later at $0.15 \mathrm{M}$ and $0.25 \mathrm{M}$ of $\mathrm{NaF}$. In fact, the current density decrease in this region was barely observed in the $0.25 \mathrm{M} \mathrm{NaF}$ solution. This can be explained by the ability of complexing ions, such as fluorides, in depressing polycondensation, due to the higher stability of the formed complexes [38]. Therefore, fluorides influenced the dissolution/precipitation mechanism in two opposite ways: the presence of fluorides increased the dissolution rate of the $\mathrm{WO}_{3}$ layer and the amount of soluble species released to the electrolyte but, at the same time, fluorides delayed or even suppressed the precipitation of tungstic acids on the electrode surface. Whether one effect or the other predominates will depend on the concentration of fluoride ions.

The Raman spectra of the samples anodized in the absence and in the presence of $\mathrm{NaF}$ $(0.1 \mathrm{M})$ are shown in Figure 2. For the rest of NaF electrolytes, the spectra were similar to those obtained at $0.1 \mathrm{M} \mathrm{NaF}$. Before the thermal treatment at $400{ }^{\circ} \mathrm{C}$ for 4 hours (Figure 2a), at least five common peaks (or regions with close peaks) could be discerned, regardless of the absence or the presence of fluorides. The peaks observed between $200-270 \mathrm{~cm}^{-1}$ can be associated with the antisymmetric stretching vibration of $(\mathrm{W}-\mathrm{O}-\mathrm{W})$ bonds in the $\mathrm{WO}_{3} \cdot \mathrm{H}_{2} \mathrm{O}$ and $\mathrm{WO}_{3} \cdot 2 \mathrm{H}_{2} \mathrm{O}$ [48] and/or bending vibration of (O$\mathrm{W}-\mathrm{O})$ bonds in amorphous $\mathrm{WO}_{3}[15,16,49-52]$. The small peaks which are distinguished at $320-350 \mathrm{~cm}^{-1}$ have also been related in the literature to bending vibration of $(\mathrm{O}-\mathrm{W}-\mathrm{O})$ bonds in amorphous $\mathrm{WO}_{3}[49,52]$, whereas the peaks at $\sim 380 \mathrm{~cm}^{-}$ ${ }^{1}$ and $\sim 430 \mathrm{~cm}^{-1}$ can be attributed to stretching modes arising from $\left(\mathrm{W}-\mathrm{OH}_{2}\right)$ and are consistent with the presence of hydrated $\mathrm{WO}_{3}[15,48]$. Finally, the broad peak centered 
at $660-670 \mathrm{~cm}^{-1}$ arises from the symmetric stretching vibration of $(\mathrm{O}-\mathrm{W}-\mathrm{O})$ bonds in hydrated $\mathrm{WO}_{3}[15,16,44,48,50-55]$ and the high peak at $\sim 960 \mathrm{~cm}^{-1}$ comes from the symmetric stretching mode of short terminal $\mathrm{W}=\mathrm{O}$ bonds [15, 21, 49-51, 53-57]. This last peak has been widely used as an indicator of amorphous tungsten trioxide hydrates (tungstic acids) $[15,55]$. A specific peak, only noticeable for the sample anodized in the $\mathrm{F}^{-}$-free electrolyte, was observed at $\sim 816 \mathrm{~cm}^{-1}$. This peak has normally been ascribed to the symmetric stretching vibration of $(\mathrm{O}-\mathrm{W}-\mathrm{O})$ bonds in crystalline $\mathrm{WO}_{3}$ (monoclinic and orthorhombic phases) [10, 15, 17, 21, 42, 52, 56, 57], although it has also been associated with the O-W-O stretching mode of hydrated samples [52].

After annealing, Raman spectra appreciably changed (Figure 2b). It can be observed that the broad band between $200-270 \mathrm{~cm}^{-1}$ turned into three separated peaks after the thermal treatment. These peaks were consequence of the bending vibration of (O-W-O) bonds in crystalline (monoclinic and orthorhombic) $\mathrm{WO}_{3}[10,15,21,52]$. Moreover, the separation of the ample peak around $660-670 \mathrm{~cm}^{-1}$ (Figure 2a) in two different peaks at $700-710 \mathrm{~cm}^{-1}$ and $800-810 \mathrm{~cm}^{-1}$ (Figure 2b), together with the disappearance of the sharp peak observed at $\sim 960 \mathrm{~cm}^{-1}$ before annealing, also indicated that the thermal treatment resulted in dehydrated crystalline $\mathrm{WO}_{3}[10,15,17,21,42,52,56,57]$. Energy-dispersive X-ray spectroscopy (EDX) analysis was also performed to elucidate whether $\mathrm{Na}^{+}$and/or $\mathrm{F}^{-}$anions could have been embedded in the $\mathrm{WO}_{3}$ structure during anodization (data not shown here), and results indicated that neither fluorides nor sodium ions were present in the $\mathrm{WO}_{3}$ nanostructures.

The morphology of the precipitated nanostructures and the influence of $\mathrm{NaF}$ concentration on the amount of precipitated tungstic acids $\left(\mathrm{WO}_{3} \cdot \mathrm{H}_{2} \mathrm{O}, \mathrm{WO}_{3} \cdot 2 \mathrm{H}_{2} \mathrm{O}\right)$ 
were studied through scanning electronic microscopy. Figure 3 shows the FESEM images of the $\mathrm{WO}_{3}$ nanostructures synthesized in $1.5 \mathrm{M} \mathrm{H}_{2} \mathrm{SO}_{4}$ electrolyte without $\mathrm{NaF}$ (Figure 3a) and with different amounts of $\mathrm{NaF}$ (Figure $3 \mathbf{b}$ to Figure 3e). Nanoplatelets were formed in all the cases, but the aggregation between them visibly changed when fluorides were present. In the absence of fluorides (Figure 3a), small nanoplatelets grew in a rather disordered way, some of them being almost orthogonal to the electrode surface while others were arranged almost horizontally. However, in the presence of $\mathrm{NaF}$, nanoplatelets grew orderly in a tree-like fashion, forming approximately globular clusters. From Figure $\mathbf{3 b}$ to Figure $3 \mathbf{e}$ it can be observed that the size of these clusters decreased with increasing NaF concentration. As it has been mentioned above, fluoride ions acted as monodentate ligands which were more strongly bound to the tungsten central atom than the $\mathrm{O}^{2-}$ ions. Hence, the presence of fluorides in the electrolyte slowed down the condensation/precipitation step, as observed above in Figure 3, hindering the formation of large nanoplatelets and favoring their aggregation in globular clusters, whose size decreased with increasing fluoride concentrations. At 0.25 M NaF, the precipitation of tungstic acids in the form of nanoplatelets barely took place (Figure 3e), since the concentration of fluorides was too high as to allow a complete polycondensation and subsequent precipitation.

The cross-sectional images of the nanoplatelets layers formed at different fluoride concentrations are presented in Figure 4. It can be seen that in the fluoride-free electrolyte, multiple graphite-like sheets of nanoplatelets were formed (Figure 4a). This nanoplatelet layer was more compact than in the presence of fluorides (Figure 4b to Figure 4d). The thickness of this layer increased with fluoride concentration up to 0.1 $\mathrm{M} \mathrm{NaF}$ and then decreased (at $0.25 \mathrm{M} \mathrm{F}^{-}$the thickness could not be determined due to 
the very small amount of precipitated nanoplatelets) (Figure 4e). These results are consistent with the current density transients obtained during the anodization process (Figure 1) and with the morphology and dimensions of the nanoplatelets globular clusters (Figure 3). In the presence of $\mathrm{F}^{-}$, and at concentrations up to $0.1 \mathrm{M} \mathrm{F}^{-}$, polycondensation of tungsten soluble species and their following precipitation in the form of tungstic acids were favored by raising the $\mathrm{F}^{-}$concentration due to the increase in the dissolution rate of the initial $\mathrm{WO}_{3}$ layer. However, at higher $\mathrm{F}^{-}$concentrations (especially $0.25 \mathrm{M}$ ), the formation of stable fluoride complexes was enhanced, making polycondensation of tungsten soluble species more difficult and, thus, preventing the formation of precipitated nanoplatelets on the electrode surface.

The photoelectrochemical performance of the samples anodized in different fluoride electrolytes is shown in Figure 5. It can be observed that the best photoresponse corresponds to the sample anodized in the $0.1 \mathrm{M} \mathrm{NaF}$ solution, which is consistent with the results presented in Figure 3 and Figure 4, where nanoplatelets globular clusters were observed to grow in a denser way and with higher layer thicknesses than in the rest of fluoride solutions. Thus, the electroactive surface area exposed to the electrolyte was at its highest point for the sample anodized in the $0.1 \mathrm{M} \mathrm{NaF}$. Next, the behavior of the samples anodized in the $\mathrm{F}^{-}$-free solution and in the presence of $0.05 \mathrm{M} \mathrm{NaF}$ was similar, reaching photocurrent density $\left(i_{p h}\right)$ values between 0.8 and $0.9 \mathrm{~mA} \mathrm{~cm}{ }^{-2}$. It has been observed in Figure 4 that the nanoplatelets layer thickness of the sample anodized in the absence of fluorides, and therefore its surface area exposed to the electrolyte, was lower than that of the samples anodized in the $0.05 \mathrm{M} \mathrm{NaF}$ solution. However, the higher degree of compaction and the morphology of the nanoplatelets in the former sample (Figure 3 and Figure 4) could lead to a better pathway for electron transport 
towards the metallic back contact, thus resulting in a better charge separation and, therefore, to similar $i_{p h}$ values in spite of having a lower surface area. The sample synthesized in the $0.15 \mathrm{M} \mathrm{NaF}$ electrolyte showed a lower response to light, due to the fact that at this concentration the thickness of the nanoplatelets layer and, especially, the degree of surface coverage by these nanostructures decreased with respect to the samples anodized in less concentrated fluoride solutions. Finally, this trend was amplified for the sample anodized in the $0.25 \mathrm{M} \mathrm{NaF}$, which barely presented photoelectrochemical behavior.

It is worth mentioning that, in all cases, current density values increased with increasing applied potentials, since the potential drop within the space charge layer and, therefore, the thickness of this layer and the strength of the electric field, directly depended on the bias potential (insofar as the space charge layer thickness can be accommodated within the semiconductor). This increase of photocurrent density with increasing potentials was approximately linear in all cases, indicating that the space charge layer could develop within the $\mathrm{WO}_{3}$ nanoplatelets without geometrical restrictions.

On the other hand, photocurrent density transients presented in Figure $\mathbf{5 b}$ demonstrate the good photostability of the samples during operation, especially the one anodized in the $0.1 \mathrm{M} \mathrm{NaF}$ solution.

\subsection{Hydrogen peroxide solutions}

The influence of hydrogen peroxide on the mechanism of formation of the $\mathrm{WO}_{3}$ nanostructures can be studied from the current density transients recorded during the 
anodization process. Figure 6 shows these current density transients for different $\mathrm{H}_{2} \mathrm{O}_{2}$ concentrations. In general, three differentiated regions can be distinguished and, in all cases, current densities were higher in the presence of $\mathrm{H}_{2} \mathrm{O}_{2}$ than in its absence. In the short zone labeled as Region I in Figure 6, current density values decreased fast, due to the formation of a compact thin film of $\mathrm{WO}_{3}$ on the electrode surface (eq. 1), as explained above for the case of fluoride solutions. Subsequently, current densities started increasing, as the thin $\mathrm{WO}_{3}$ film dissolved due to the action of $\mathrm{H}^{+}$(eq. 2) and, principally, due to the effect of $\mathrm{H}_{2} \mathrm{O}_{2}$ (Region II, Figure 6). The peroxo group $\left(\mathrm{O}_{2}{ }^{2-}\right)$ is a well-known bidentate ligand for tungsten species, substituting the $\mathrm{O}^{2-}$ ligands at the tungstate ion. Hydrogen peroxide reacts with tungstates and $\mathrm{WO}_{3}$ to form peroxotungstates and peroxotungstic acids. In acidic solutions, the prevalent peroxotungstate is the dinuclear $\mathrm{W}_{2} \mathrm{O}_{11}{ }^{2-}[28,58]$. This compound results from the $\mathrm{WO}_{3}$ dissolution by the action of $\mathrm{H}_{2} \mathrm{O}_{2}$ via the following equation:

$$
2 \mathrm{WO}_{3}+4 \mathrm{H}_{2} \mathrm{O}_{2} \rightarrow\left[\mathrm{W}_{2} \mathrm{O}_{11}\right]^{2-}+2 \mathrm{H}^{+}+3 \mathrm{H}_{2} \mathrm{O}
$$

The complex $\left[\mathrm{W}_{2} \mathrm{O}_{11}\right]^{2-}$ can also be obtained by direct reaction between the tungsten substrate and hydrogen peroxide, according to [28, 38]:

$$
2 \mathrm{~W}+10 \mathrm{H}_{2} \mathrm{O}_{2} \rightarrow\left[\mathrm{W}_{2} \mathrm{O}_{11}\right]^{2-}+2 \mathrm{H}^{+}+9 \mathrm{H}_{2} \mathrm{O}
$$

After reaching a maximum value, current densities decreased again in Region III (Figure 6), due to the precipitation of tungstic acids $\left(\mathrm{WO}_{3} \cdot \mathrm{H}_{2} \mathrm{O}\right.$ and $\left.\mathrm{WO}_{3} \cdot 2 \mathrm{H}_{2} \mathrm{O}\right)$ from polytungstates and peroxotungstates. This precipitation took place when supersaturation conditions were reached. Besides, since peroxotungstates are thermodynamically 
unstable, they slowly decomposed. In particular, $\mathrm{W}_{2} \mathrm{O}_{11}{ }^{2-}$ can decompose into solid $\mathrm{WO}_{3}$, according to [28]:

$$
\mathrm{W}_{2} \mathrm{O}_{11}^{2-}+2 \mathrm{H}^{+} \rightarrow 2 \mathrm{WO}_{3}+2 \mathrm{O}_{2}+\mathrm{H}_{2} \mathrm{O}
$$

Is it noteworthy that this Region III started later as the $\mathrm{H}_{2} \mathrm{O}_{2}$ concentration increased, and current density values increased with increasing $\mathrm{H}_{2} \mathrm{O}_{2}$ concentration, which is consistent with higher dissolution and substrate oxidation rates, according to eqs. (6) and (1), respectively. These results can be explained by taking into account that the presence of complexing agents, such as hydrogen peroxide, prevented the polycondensation tendency of tungsten species [38], since the bond between tungsten and the $\mathrm{O}_{2}{ }^{2-}$ ligand was more stable than the bond between tungsten and $\mathrm{O}^{2-}$. In the 0.2 $\mathrm{M} \mathrm{H}_{2} \mathrm{O}_{2}$ solution, the concentration was high enough so as to significantly delay the precipitation of tungstic acids and, when formed, to favor their redissolution via eq. (6).

To study the influence of $\mathrm{H}_{2} \mathrm{O}_{2}$ on the composition and crystalline structure of the formed nanostructures, Raman spectroscopy was carried out for all the samples. Figure 7 shows the Raman spectra of samples anodized in the peroxide-free solution and in the $0.05 \mathrm{M}$ and $0.1 \mathrm{M} \mathrm{H}_{2} \mathrm{O}_{2}$ solutions, before and after the thermal treatment. The samples anodized in higher $\mathrm{H}_{2} \mathrm{O}_{2}$ solutions showed similar spectra as those of the sample synthesized in the $0.1 \mathrm{M} \mathrm{H}_{2} \mathrm{O}_{2}$ solution, so they are not presented here.

The spectra obtained before the heat treatment (Figure 7a) presents two remarkable features which were not observed in the samples anodized in the presence of fluoride (Figure 2a): (1) the high peak observed at $816 \mathrm{~cm}^{-1}$ for the samples anodized in the $\mathrm{H}_{2} \mathrm{O}_{2}$ solutions was not observed for the samples anodized in the fluoride solutions (it 
was only visible in the $\mathrm{F}^{-}$-free solution (Figure 2a)); as explained above, this peak has been associated with crystalline forms of $\mathrm{WO}_{3}[10,15,17,21,42,52,56,57]$; (2) for the sample synthesized in the $0.05 \mathrm{M} \mathrm{H}_{2} \mathrm{O}_{2}$ solution, the peak at $\sim 960 \mathrm{~cm}^{-1}$, which has been regarded as a marker for amorphous $\mathrm{WO}_{3} \cdot x \mathrm{H}_{2} \mathrm{O}[15,55]$, disappeared almost completely, although it was still visible for the sample anodized in the $0.1 \mathrm{M} \mathrm{H}_{2} \mathrm{O}_{2}$ (as well as in the peroxide-free solution). These differences in the spectra with respect to those obtained in the presence of fluorides (Figure 2a) indicate that the precipitated formed on the samples anodized in $\mathrm{H}_{2} \mathrm{O}_{2}$ solutions were significantly less hydrated than those formed on the fluoride electrolytes. This is a result of the thermodynamic instability of peroxotungstates, which decompose into dehydrated $\mathrm{WO}_{3}$ (eq. 8). Therefore, the decomposition of peroxotungstates played an important role in the formation of the nanostructures. This fact is especially remarkable for the sample anodized in the $0.05 \mathrm{M} \mathrm{H}_{2} \mathrm{O}_{2}$ solution, where this decomposition process seemed to predominate over the precipitation of tungstic acids.

The spectra obtained after the heat treatment (Figure 7b) are similar to those obtained for the samples synthesized in the fluoride solutions (Figure 2b). Hence, after subjecting the samples to $400{ }^{\circ} \mathrm{C}$ for $4 \mathrm{~h}$, crystalline $\mathrm{WO}_{3}$ was obtained in all cases.

Concerning the morphology of the formed nanostructures, it can be observed from the FESEM images in Figure 8 that they are very different from those formed in the presence of fluorides (Figure 3). In general, very small nanoplatelets or nanosheets were formed on the tungsten surface, forming a kind of spongy layer. These nanosheets aggregated forming cones or "mountains", whose size increased with increasing $\mathrm{H}_{2} \mathrm{O}_{2}$ concentration. At intermediate $\mathrm{H}_{2} \mathrm{O}_{2}$ concentrations $(0.1 \mathrm{M}$ and $0.15 \mathrm{M})$, vein-like 
accumulations of nanosheets seemed to form over the top part of the cones. In the $0.2 \mathrm{M}$ $\mathrm{H}_{2} \mathrm{O}_{2}$ solution, the mountainous shape disappeared and only veined forms could be distinguished. Moreover, at high $\mathrm{H}_{2} \mathrm{O}_{2}$ concentrations, especially in the $0.2 \mathrm{M} \mathrm{H}_{2} \mathrm{O}_{2}$ solution, big holes could be observed distributed throughout the surface (a general view of the electrode surface is presented as inset in Figure 8g), which indicates a redissolution of the $\mathrm{WO}_{3}$ nanostructure by the action of $\mathrm{H}_{2} \mathrm{O}_{2}$ (eq. (6)). The differences observed in morphology can be related to an alteration in the mechanism of formation of the nanostructures, changing from a process in which peroxotungstate decomposition to form dehydrated $\mathrm{WO}_{3}$ predominated (at low $\mathrm{H}_{2} \mathrm{O}_{2}$ concentrations, especially $0.05 \mathrm{M}$ ) to a tungstic acid $\left(\mathrm{WO}_{3} \cdot x \mathrm{H}_{2} \mathrm{O}\right)$ precipitation mechanism as $\mathrm{H}_{2} \mathrm{O}_{2}$ concentration increased.

The very small size of the new nanoplatelets or nanosheets, compared with the ones formed in the presence of fluorides (Figure 3) or in the $1.5 \mathrm{M} \mathrm{H}_{2} \mathrm{SO}_{4}$ solution (in the absence of ligands, Figure 3a) is related to the tendency of the bidentate $\mathrm{O}_{2}{ }^{2-}$ ligand to form stronger bonds with tungsten than the monodentate $\mathrm{F}^{-}$(and $\mathrm{O}^{2-}$ ). This fact resulted in a slowing down of the decomposition or precipitation rate of peroxotungstates, preventing the nanoplatelets/nanosheets from growing, so their size decreased [42].

Figure 9 shows the cross-sectional views of the nanostructures formed in the presence of $\mathrm{H}_{2} \mathrm{O}_{2}$. In all cases, many small nanoplatelets/nanosheets ordered in multilayers could be observed. These nanosheets were packed in a more compact way than those formed in the presence of $\mathrm{F}^{-}$(see Figure 4 for comparison). No morphological change was observed with increasing $\mathrm{H}_{2} \mathrm{O}_{2}$ concentration. In the concentration range from $0.05 \mathrm{M}$ to $0.15 \mathrm{M}$, the thickness of the nanosheet layer increased with respect to that obtained in 
the blank (peroxide-free) electrolyte (Figure 9e). This increase is related to the higher dissolution rate of the initial $\mathrm{WO}_{3}$ film due to the action of $\mathrm{H}_{2} \mathrm{O}_{2}$ (eq. 6) which resulted, in turn, in a higher amount of deposited $\mathrm{WO}_{3}$. However, at $0.2 \mathrm{M} \mathrm{H}_{2} \mathrm{O}_{2}$, the thickness of this layer decreased significantly, since the peroxide concentration was too high and the deposition of the nanostructures was somewhat impeded, as explained above.

The photocurrent density vs. potential curves and photocurrent density transients for the $\mathrm{WO}_{3}$ nanostructures synthesized in $\mathrm{H}_{2} \mathrm{O}_{2}$ solutions are shown in Figure 10a and Figure 10b, respectively. In this case, all the samples anodized in the presence of $\mathrm{H}_{2} \mathrm{O}_{2}$ presented higher photoresponses than the sample anodized in the $1.5 \mathrm{M} \mathrm{H}_{2} \mathrm{SO}_{4}$ solution (without $\mathrm{H}_{2} \mathrm{O}_{2}$ ). Besides, a low $\mathrm{H}_{2} \mathrm{O}_{2}$ concentration in the anodizing electrolyte (0.05 M $\mathrm{H}_{2} \mathrm{O}_{2}$ ) resulted in the highest photoelectrochemical performance, while photoelectrodes synthesized in the $0.1 \mathrm{M}$ and $0.15 \mathrm{M} \mathrm{H}_{2} \mathrm{O}_{2}$ solutions presented a more or less similar behavior. The sample produced in the more concentrated solution $\left(0.2 \mathrm{M} \mathrm{H}_{2} \mathrm{O}_{2}\right)$ gave appreciably lower photocurrent densities. These results are a consequence of the nanostructures morphology and dimensions. As observed in the FESEM images (Figure 8), the cones or "mountains" formed by little nanoplatelets/nanosheets were smaller in the $0.05 \mathrm{M} \mathrm{H}_{2} \mathrm{O}_{2}$ solution than in the more concentrated ones, leading to higher surface area exposed to the electrolyte and, therefore, to higher photocurrent densities upon illumination. The comparable results obtained for the nanostructures fabricated in the $0.1 \mathrm{M}$ and $0.15 \mathrm{M} \mathrm{H}_{2} \mathrm{O}_{2}$ solutions are in accordance with their similar morphology and size (Figures 8c-8f), while the absence of an ordered morphology in the sample anodized in the $0.2 \mathrm{M} \mathrm{H}_{2} \mathrm{O}_{2}$ solution (Figures $8 \mathbf{g}$ and $\mathbf{8 h}$ ) resulted in a considerably lower photoactivity, although it was still better than the sample anodized in the peroxide-free electrolyte. 
It is important to point out that the sample anodized in $0.05 \mathrm{M} \mathrm{H}_{2} \mathrm{O}_{2}$ yielded higher photocurrent densities than the best sample anodized in the presence of fluoride anions (0.1 M NaF), regardless of the applied potential. This improvement of photocurrent can be attributed to enhanced electron transport towards the metallic back contact arising from the morphology of the nanostructure obtained in the presence of $\mathrm{H}_{2} \mathrm{O}_{2}$, whose structure was more compact than that obtained in the presence of $\mathrm{F}^{-}$. Hence, a more effective separation of photogenerated charges could be achieved. Moreover, the surface area of the nanoplatelets formed in the $0.05 \mathrm{M} \mathrm{H}_{2} \mathrm{O}_{2}$ solution could be higher than the area of those formed in the presence of fluoride anions, due to the lower nanoplatelet/nanosheet dimensions obtained in the former case.

On the other hand, it can be observed from $i_{p h}-U$ curves in Figure 10a that, although photocurrent density values increased with increasing potential, this increase was not linear, contrary to what occurred in the case of photoanodes synthesized in $\mathrm{NaF}$ electrolytes. In the present case, photocurrent densities drastically increased until a potential of $\sim 0.7 \mathrm{VAg} / \mathrm{AgCl}$ was reached, and then this increase was slowed down or even stopped. This partial (or complete) saturation of photocurrent density at high applied potentials could be related to the width of the space charge layer being constricted by the very small dimensions of the $\mathrm{WO}_{3}$ nanoplatelets/nanosheets formed in the presence of $\mathrm{H}_{2} \mathrm{O}_{2}$. Hence, in this case, at high bias potentials, the space charge layer would reach its maximum possible width, that is, the thickness of the nanoplatelets [59, 60], which would become completely depleted. This fact can be a positive one, since it reduces the applied potential needed to reach the maximum value of photocurrent density and, thus, increases the efficiency of photoelectrochemical processes [61]. 
Finally, the photostability of the samples anodized in $\mathrm{H}_{2} \mathrm{O}_{2}$ solutions showed a satisfactory photostability, as confirmed by the photocurrent density transients shown in Figure 10b.

\section{Conclusions}

Nanoplatelet globular clusters associated in a tree-like manner and formed by precipitation of tungstic acids $\left(\mathrm{WO}_{3} \cdot x \mathrm{H}_{2} \mathrm{O}\right)$ were obtained by anodization of tungsten in the presence of fluoride ions. At low fluoride concentrations (up to $0.1 \mathrm{M}$ ) the amount of formed nanoplatelets, and therefore the surface area exposed to the electrolyte under illumination, increased, but at higher concentrations the excess of fluorides resulted in a delay or even suppression of nanoplatelets precipitation. The optimum concentration for photoelectrochemical applications was found to be $0.1 \mathrm{M} \mathrm{NaF}$, with an increase in photocurrent density of $64 \%$ at $0.7 \mathrm{~V}_{\mathrm{Ag} / \mathrm{AgCl}}$ compared with conventional nanoplatelets (synthesized without ligands).

Very small nanoplatelets/nanosheets composed of (partially) dehydrated $\mathrm{WO}_{3}$ were obtained by anodization in acidic $\mathrm{H}_{2} \mathrm{O}_{2}$ solutions. This particular form in which nanosheets aggregated led to enhanced the charge transfer and charge separation. An excess of $\mathrm{H}_{2} \mathrm{O}_{2}$, which acted as a powerful ligand with tungstates, led to a reduction in the photoactivity of the nanostructures. The optimum concentration for photoelectrochemical applications was $0.05 \mathrm{M} \mathrm{H}_{2} \mathrm{O}_{2}$, with an increase in photocurrent density of $244 \%$ at $0.7 \mathrm{~V}_{\mathrm{Ag} / \mathrm{AgCl}}$ compared with conventional nanoplatelets. 
The photoanode synthesized in the $0.05 \mathrm{M} \mathrm{H}_{2} \mathrm{O}_{2}$ solution, apart from producing higher photocurrent densities than the obtained with the photoanodes anodized in $\mathrm{NaF}$ solutions (at all applied potentials), could operate at lower bias potentials and, therefore, increase the efficiency of photoelectrochemical processes.

Acknowledgements: Authors would like to express their gratitude for the financial support to the Ministerio of Economía y Competitividad (Project CTQ2013-42494-R), for its help in the Laser Raman Microscope acquisition (UPOV08-3E-012) and for the co-finance by the European Social Fund.

\section{REFERENCES}

[1] H. Zheng, J. Z. Ou, M. S. Strano, R. B. Kaner, A. Mitchell, K. Kalantar-zadeh. Nanostructured Tungsten Oxide - Properties, Synthesis, and Applications, Adv. Funct. Mater. 21 (2011) 2175-2196.

[2] C. A. Bignozzi, S. Caramori, V. Cristino, R. Argazzi, L. Meda, A. Tacca. Nanostructured photoelectrodes based on $\mathrm{WO}_{3}$ : applications to photooxidation of aqueous electrolytes, Chem. Soc. Rev. 42 (2013) 2228-2246.

[3] S. S. Kalanur, Y. J. Hwang, S. Y. Chae, O. S. Joo. Facile growth of aligned $\mathrm{WO}_{3}$ nanorods on FTO substrate for enhanced photoanodic water oxidation activity, J. Mater. Chem. A 1 (2013) 3479-3488.

[4] W. Li, P. Da, Y. Zhang, Y. Wang, X. Lin, X. Gong, G. Zheng. $\mathrm{WO}_{3}$ Nanoflakes for Enhanced Photoelectrochemical Conversion, ACS Nano 8 (2014) 11770-11777.

[5] R. M. Fernández-Domene, R. Sánchez-Tovar, E. Segura-Sanchís, J. GarcíaAntón. Novel Tree-Like $\mathrm{WO}_{3}$ Nanoplatelets with Very High Surface Area Synthesized by Anodization Under Controlled Hydrodynamic Conditions, Chem. Eng. J. 286 (2015) 59-67.

[6] R. M. Fernández-Domene, R. Sánchez-Tovar, B. Lucas-Granados, J. GarcíaAntón. Improvement in photocatalytic activity of stable $\mathrm{WO}_{3}$ nanoplatelet globular clusters arranged in a tree-like fashion: Influence of rotation velocity during anodization, Appl. Catal. B Environ. 189 (2016) 266-282. 
[7] C. W. Lai. Photocatalysis and Photoelectrochemical Properties of Tungsten Trioxide Nanostructured Films, The Scientific World J. 2014 (2014) 843587 (7pp).

[8] A. Watcharenwong, W. Chanmanee, N. R. de Tacconi, C. R. Chenthamarakshan, P. Kajitvichyanukul, K. Rajeshwar. Anodic growth of nanoporous $\mathrm{WO}_{3}$ films: Morphology, photoelectrochemical response and photocatalytic activity for methylene blue and hexavalent chrome conversion, J. Electroanal. Chem. 612 (2008) 112-120.

[9] C. W. Lai, S. Sreekantan. Fabrication of $\mathrm{WO}_{3}$ nanostructures by anodization method for visible-light driven water splitting and photodegradation of methyl orange, Mat. Sci. Semicon. Proc. 16 (2013) 303-310.

[10] H. Song, Y. Li, Z. Lou, M. Xiao, L. Hu, Z. Ye, L. Zhu. Synthesis of Fe-doped $\mathrm{WO}_{3}$ nanostructures with high visible-light-driven photocatalytic activities, Appl. Catal. B-Environ. 166-167 (2015) 112-120.

[11] J. Z. Ou, R. A. Rani, S. Balendhran, A. S. Zoolfakar, M. R. Field, S. Zhuiykov, A. P. O'Mullane, K. Kalantar-zadeh. Anodic formation of a thick three-dimensional nanoporous $\mathrm{WO}_{3}$ film and its photocatalytic property, Electrochem. Commun. 27 (2013) 128-132.

[12] Q. Chen, J. Li, B. Zhou, M. Long, H. Chen, Y. Liu, W. Cai, W. Shangguan. Preparation of well-aligned $\mathrm{WO}_{3}$ nanoflake arrays vertically grown on tungsten substrate as photoanode for photoelectrochemical water splitting, Electrochem. Commun. 20 (2012) 153-156.

[13] C. Santato, M. Ulmann, J. Augustynski. Photoelectrochemical Properties of Nanostructured Tungsten Trioxide Films, J. Phys. Chem. B 105 (2001) 936940.

[14] R. Liu, Y. Lin, L. Y. Chou, S. W. Sheehan, W. He, F. Zhang, H. J. M. Hou, D. Wang. Water Splitting by Tungsten Oxide Prepared by Atomic Layer Deposition and Decorated with an Oxygen-Evolving Catalyst, Angew. Chem. Int. Ed. 50 (2011) 499-502.

[15] A. Z. Sadek, H. Zheng, M. Breedon, V. Bansal, S. K. Bhargava, K. Latham, J. Zhu, L. Yu, Z. Hu, P. G. Spizzirri, W. Wlodarski, K. Kalantar-zadeh. HighTemperature Anodized $\mathrm{WO}_{3}$ Nanoplatelet Films for Photosensitive Devices, Langmuir 25 (2009) 9545-9551.

[16] J. Z. Ou, M. H. Yaacob, J. L. Campbell, M. Breedon, K. Kalantar-zadeh, W. Wlodarski. $\mathrm{H}_{2}$ sensing performance of optical fiber coated with nano-platelet $\mathrm{WO}_{3}$ film, Sensor. Actuat. B-Chem. 166-167 (2012) 1-6.

[17] A. Rougier, F. Portemer, A. Quédé, M. El Marssi. Characterization of pulsed laser deposited $\mathrm{WO}_{3}$ thin films for electrochromic devices, Appl. Surf. Sci. 153 (1999) 1-9. 
[18] J. Z. Ou, S. Balendhran, M. R. Field, D. G. McCulloch, A. S. Zoolfakar, R. A. Rani, S. Zhuiykov, A. P. O'Mullane, K. Kalantar-zadeh. The anodized crystalline $\mathrm{WO}_{3}$ nanoporous network with enhanced electrochromic properties, Nanoscale 4 (2012) 5980-5988.

[19] Y. C. Nah, A. Ghicov, D. Kim, P. Schmuki. Enhanced electrochromic properties of self-organized nanoporous $\mathrm{WO}_{3}$, Electrochem. Commun. 10 (2008) 1777-1780.

[20] R. van de Krol, Principles of Photoelectrochemical Cells, in: R. van de Krol, M. Grätzel (eds.), Photoelectrochemical Hydrogen Production, New York, 2012, 13-67.

[21] F. Amano, M. Tian, B. Ohtani, A. Chen. Photoelectrochemical properties of tungsten trioxide thin film electrodes prepared from facet-controlled rectangular platelets, J. Solid State Electrochem. 16 (2012) 1965-1973.

[22] G. Wang, Y. Ling, H. Wang, X. Yang, C. Wang, J. Z. Zhang, Y. Li. Hydrogen-treated $\mathrm{WO}_{3}$ nanoflakes show enhanced photostability, Energy Environ. Sci. 5 (2012) 6180-6187.

[23] J. Su, X. Feng, J. D. Sloppy, L. Guo, C. A. Grimes. Vertically Aligned $\mathrm{WO}_{3}$ Nanowire Arrays Grown Directly on Transparent Conducting Oxide Coated Glass: Synthesis and Photoelectrochemical Properties, Nano Lett. 11 (2011) 203-208.

[24] M. Yagi, S. Maruyama, K. Sone, K. Nagai, T. Norimatsu. Preparation and photoelectrocatalytic activity of a nano-structured $\mathrm{WO}_{3}$ platelet film, J. Solid State Chem. 181 (2008) 175-182.

[25] R. Solarska, R. Jurczakowski, J. Augustynski. A highly stable, efficient visible-light driven water photoelectrolysis system using a nanocrystalline $\mathrm{WO}_{3}$ photoanode and a methane sulfonic acid electrolyte, Nanoscale 4 (2012) 1553-1556.

[26] J. C. Hill, K. S. Choi. Effect of Electrolytes on the Selectivity and Stability of n-type $\mathrm{WO}_{3}$ Photoelectrodes for Use in Solar Water Oxidation, J. Phys. Chem. C 116 (2012) 7612-7620.

[27] D. Monllor-Satoca, L. Borja, A. Rodes, R. Gómez, P. Salvador. Photoelectrochemical Behavior of Nanostructured $\mathrm{WO}_{3}$ Thin-Film Electrodes: The Oxidation of Formic Acid, ChemPhysChem 7 (2006) 2540-2551.

[28] E. A. Meulenkamp. Mechanism of $\mathrm{WO}_{3}$ Electrodeposition from PeroxyTungstate Solution, J. Electrochem. Soc. 144 (1997) 1664-1671.

[29] T. Zhu, M. N. Chong, Y. W. Phuan, E. S. Chan. Electrochemically synthesized tungsten trioxide nanostructures for photoelectrochemical water splitting: Influence of heat treatment on physicochemical properties, photocurrent densities and electron shuttling, Colloid. Surface. A 484 (2015) 297-303. 
[30] S. Poongodi, P. S. Kumar, Y. Masuda, D. Mangalaraj, N. Ponpandian, C. Viswanathan, S. Ramakrishna. Synthesis of hierarchical $\mathrm{WO}_{3}$ nanostructured thin films with enhanced electrochromic performance for switchable smart windows, RSC Adv. 5 (2015) 96416-96427.

[31] S. H. Baeck, T. Jaramillo, G. D. Stucky, E. W. McFarland. Controlled Electrodeposition of Nanoparticulate Tungsten Oxide, Nano Lett. 2 (2002) 831-834.

[32] M. Deepa, A. K. Srivastava, S. N. Sharma, Govind, S. M. Shivaprasad. Microstructural and electrochromic properties of tungsten oxide thin films produced by surfactant mediated electrodeposition, Appl. Surf. Sci. 254 (2008) 2342-2352.

[33] V. Chakrapani, J. Thangala, M. K. Sunkara. $\mathrm{WO}_{3}$ and $\mathrm{W}_{2} \mathrm{~N}$ nanowire arrays for photoelectrochemical hydrogen production, Int. J. Hydrogen Energ. 34 (2009) 9050-9059.

[34] J. M. Spurgeon, J. M. Velazquez, M. T. McDowell. Improving $\mathrm{O}_{2}$ production of $\mathrm{WO}_{3}$ photoanodes with $\mathrm{IrO}_{2}$ in acidic aqueous electrolyte, Phys. Chem. Chem. Phys. 16 (2014) 3623-3631.

[35] G. H. Go, P. S. Shinde, C. H. Doh, W. J. Lee, PVP-assisted synthesis of nanostructured transparent $\mathrm{WO}_{3}$ thin films for photoelectrochemical water splitting, Mater. Design 90 (2016) 1005-1009.

[36] H. Fan, Z. Wu, T. Sun, M. Yang, J. Guo, K. Yang, Y. Li, Efficient plasmaassisted approach in nanostructure fabrication of tungsten, Mater. Design 89 (2016) 78-84.

[37] K. Kalantar-zadeh, A. Z. Sadek, H. Zheng, V. Bansal, S. K. Bhargava, W. Wlodarski, J. Zhu, L. Yu, Z. Hu. Nanostructured $\mathrm{WO}_{3}$ films using high temperature anodization, Sensor. Actuat. B-Chem. 142 (2009) 230-235.

[38] E. Lassner and W. D. Schubert, Tungsten. Properties, Chemistry, Technology of the Element, Alloys, and Chemical Compounds, Kluwer Academic / Plenum Publishers, New York, 1999.

[39] M. Yang, N. K. Shrestha, P. Schmuki. Thick porous tungsten trioxide films by anodization of tungsten in fluoride containing phosphoric acid electrolyte, Electrochem. Commun. 11 (2009) 1908-1911.

[40] W. Li, J. Li, X. Wang, S. Luo, J. Xiao, Q. Chen. Visible light photoelectrochemical responsiveness of self-organized nanoporous $\mathrm{WO}_{3}$ films, Electrochim. Acta 56 (2010) 620-625.

[41] J. W. J. Hamilton, J. A. Byrne, P. S. M. Dunlop, N. M. D. Brown. PhotoOxidation of Water Using Nanocrystalline Tungsten Oxide under Visible Light, Int. J. Photoenergy 2008 (2008) 185479 (5pp). 
[42] Z. Lu, S. M. Kanan, C. P. Tripp. Synthesis of high surface area monoclinic $\mathrm{WO}_{3}$ particles using organic ligands and emulsion based methods, J. Mater. Chem. 12 (2002) 983-989.

[43] J. Yang, W. Li, J. Li, D. Sun, Q. Chen. Hydrothermal synthesis and photoelectrochemical properties of vertically aligned tungsten trioxide (hydrate) plate-like arrays fabricated directly on FTO substrates, J. Mater. Chem. 22 (2012) 17744-17752.

[44] J. H. Ha, P. Muralidharan, D. K. Kim. Hydrothermal synthesis and characterization of self-assembled $\mathrm{h}-\mathrm{WO}_{3}$ nanowires/nanorods using EDTA salts, J. Alloy. Compd. 475 (2009) 446-451.

[45] N. R. de Tacconi, C. R. Chenthamarakshan, G. Yogeeswaran, A. Watcharenwong, R. S. de Zoysa, N. A. Basit, K. Rajeshwar. Nanoporous $\mathrm{TiO}_{2}$ and $\mathrm{WO}_{3}$ Films by Anodization of Titanium and Tungsten Substrates: Influence of Process Variables on Morphology and Photoelectrochemical Response, J. Phys. Chem. B 110 (2006) 25347-25355.

[46] A. Di Paola, F. Di Quarto, C. Sunseri. Anodic oxide films on tungsten I. The influence of anodizing parameters on charging curves and film composition, Corros. Sci. 20 (1980) 1067-1078.

[47] C. Ng, C. Ye, Y. H. Ng, R. Amal. Flower-Shaped Tungsten Oxide with Inorganic Fullerene-like Structure: Synthesis and Characterization, Cryst. Growth Des. 10 (2010) 3794-3801.

[48] M. F. Daniel, B. Desbat, J. C. Lassegues, B. Gerand, M. Figlarz. Infrared and Raman study of $\mathrm{WO}_{3}$ tungsten trioxides and $\mathrm{WO}_{3}, \mathrm{xH}_{2} \mathrm{O}$ tungsten trioxide tydrates, J. Solid State Chem. 67 (1987) 235-247.

[49] J. Díaz-Reyes, V. Dorantes-García, A. Pérez-Benítez, J. A. Balderas-López. Obtaining of films of tungsten trioxide $\left(\mathrm{WO}_{3}\right)$ by resistive heating of a tungsten filament, Superficies y Vacío 21 (2008) 12-17.

[50] S. H. Lee, H. M. Cheong, C. E. Tracy, A. Mascarenhas, D. K. Benson, S. K. Deb. Raman spectroscopic studies of electrochromic a- $\mathrm{WO}_{3}$, Electrochim. Acta 44 (1999) 3111-3115.

[51] K. M. Karuppasamy, A. Subrahmanyam. Results on the electrochromic and photocatalytic properties of vanadium doped tungsten oxide thin films prepared by reactive dc magnetron sputtering technique, J. Phys. D Appl. Phys. 41 (2008) 035302.

[52] B. Pecquenard, H. Lecacheux, J. Livage, C. Julien. Orthorhombic $\mathrm{WO}_{3}$ Formed via a Ti-Stabilized $\mathrm{WO}_{3} \cdot 13 \mathrm{H}_{2} \mathrm{O}$ Phase, J. Solid State Chem. 135 (1998) 159-168.

[53] C. K. Wang, C. K. Lin, C. L. Wu, S. C. Wang, J. L. Huang. Synthesis and characterization of electrochromic plate-like tungsten oxide films by acidic treatment of electrochemical anodized tungsten, Electrochim. Acta 112 (2013) 24-31. 
[54] S. H. Lee, H. M. Cheong, C. E. Tracy, A. Mascarenhas, A. W. Czanderna. Electrochromic coloration efficiency of a- $\mathrm{WO}_{3-y}$ thin films as a function of oxygen deficiency, Appl. Phys. Lett. 75 (1999) 1541-1543.

[55] C. Santato, M. Odziemkowski, M. Ulmann, J. Augustynski. Crystallographically Oriented Mesoporous $\mathrm{WO}_{3}$ Films: Synthesis, Characterization, and Applications, J. Am. Chem. Soc. 123 (2001) 1063910649.

[56] C. Bittencourt, R. Landers, E. Llobet, X. Correig, J. Calderer. The role of oxygen partial pressure and annealing temperature on the formation of $\mathrm{W}=\mathrm{O}$ bonds in thin $\mathrm{WO}_{3}$ films, Semicond. Sci. Technol. 17 (2002) 522-525.

[57] A. G. Souza-Filho, V. N. Freire, J. M. Sasaki, J. Mendes Filho, J. F. Julião, U. U. Gomes. Coexistence of triclinic and monoclinic phases in $\mathrm{WO}_{3}$ ceramics, J. Raman Spectrosc. 31 (2000) 451-454.

[58] N. J. Campbell, A. C. Dengel, C. J. Edwards, W. P. Griffith. Studies on transition metal peroxo complexes. Part 8. The nature of peroxomolybdates and peroxotungstates in aqueous solution, J. Chem. Soc. Dalton Trans. (1989) 1203-1208.

[59] L. k. Tsui, M. Saito, T. Homma, G. Zangari. Trap-state passivation of titania nanotubes by electrochemical doping for enhanced photoelectrochemical performance, J. Mater. Chem. A 3 (2015) 360-367.

[60] S. Palmas, A. Da Pozzo, M. Mascia, A. Vacca, A. Ardu, R. Matarrese, I. Nova. Effect of the preparation conditions on the performance of $\mathrm{TiO}_{2}$ nanotube arrays obtained by electrochemical oxidation, Int. J. Hydrogen Energ. 36 (2011) 8894-8901.

[61] G. Wang, H. Wang, Y. Ling, Y. Tang, X. Yang, R. C. Fitzmorris, C. Wang, J. Z. Zhang, Y. Li. Hydrogen-Treated $\mathrm{TiO}_{2}$ Nanowire Arrays for Photoelectrochemical Water Splitting, Nano Lett. 11 (2011) 3026-3033. 


\section{Figures captions}

Figure 1. Current density transient recorded during anodization in different $\mathrm{NaF}$ solutions, as well as in the absence of complexing agents (blank).

Figure 2. Raman spectra of the samples anodized in the $\mathrm{F}^{-}$-free (blank) and $0.1 \mathrm{M} \mathrm{NaF}$ solutions, (a) before the heat treatment and (b) after the heat treatment at $400^{\circ} \mathrm{C}$ for $4 \mathrm{~h}$.

Figure 3. FESEM images of the $\mathrm{WO}_{3}$ nanostructures formed upon anodization of $\mathrm{W}$ in a $1.5 \mathrm{M} \mathrm{H}_{2} \mathrm{SO}_{4}+\mathrm{NaF}$ electrolytes at $50^{\circ} \mathrm{C}$, imposing a potential of $20 \mathrm{~V}$ for 4 hours, at different $\mathrm{NaF}$ concentrations and in the absence of complexing agents (blank).

Figure 4. FESEM cross-sectional images of samples anodized in the different NaF electrolytes and in the absence of complexing agents (blank) (a-d); nanoplatelets layer thickness as a function of the NaF concentration (e).

Figure 5. (a) Photocurrent density $\left(i_{p h}\right)$ vs. potential $(U)$ curves of the $\mathrm{WO}_{3}$ nanoplatelets formed in different $\mathrm{NaF}$ solutions and in the absence of complexing agents (blank), measured in a $65 \mathrm{~mol} \% \mathrm{CH}_{3} \mathrm{OH}$ with $5 \mathrm{M} \mathrm{LiCl}$ solution under AM1.5 illumination. (b) Photocurrent density transients obtained under illumination at an applied potential of $1.02 \mathrm{VAg} / \mathrm{AgCl}$. 
Figure 6. Current density transient recorded during anodization in different $\mathrm{H}_{2} \mathrm{O}_{2}$ solutions, as well as in the absence of complexing agents (blank).

Figure 7. Raman spectra of the samples anodized in the $\mathrm{H}_{2} \mathrm{O}_{2}-$ free (blank), $0.05 \mathrm{M}$ and $0.1 \mathrm{M} \mathrm{H}_{2} \mathrm{O}_{2}$ solutions, (a) before the heat treatment and (b) after the heat treatment at $400^{\circ} \mathrm{C}$ for $4 \mathrm{~h}$.

Figure 8. FESEM images of the $\mathrm{WO}_{3}$ nanostructures formed upon anodization of $\mathrm{W}$ in a $1.5 \mathrm{M} \mathrm{H}_{2} \mathrm{SO}_{4}+\mathrm{H}_{2} \mathrm{O}_{2}$ electrolytes at $50^{\circ} \mathrm{C}$, imposing a potential of $20 \mathrm{~V}$ for 4 hours, at different $\mathrm{H}_{2} \mathrm{O}_{2}$ concentrations.

Figure 9. FESEM cross-sectional images of samples anodized in the different $\mathrm{H}_{2} \mathrm{O}_{2}$ electrolytes (a-d); nanoplatelets layer thickness as a function of the $\mathrm{H}_{2} \mathrm{O}_{2}$ concentration (e).

Figure 10. (a) Photocurrent density $\left(i_{p h}\right)$ vs. potential $(U)$ curves of the $\mathrm{WO}_{3}$ nanoplatelets formed in different $\mathrm{H}_{2} \mathrm{O}_{2}$ solutions and in the absence of complexing agents (blank), measured in a $65 \mathrm{~mol} \% \mathrm{CH}_{3} \mathrm{OH}$ with $5 \mathrm{M} \mathrm{LiCl}$ solution under AM1.5 illumination. (b) Photocurrent density transients obtained under illumination at an applied potential of $1.02 \mathrm{~V}$ Ag/AgCl. 
Figure 1

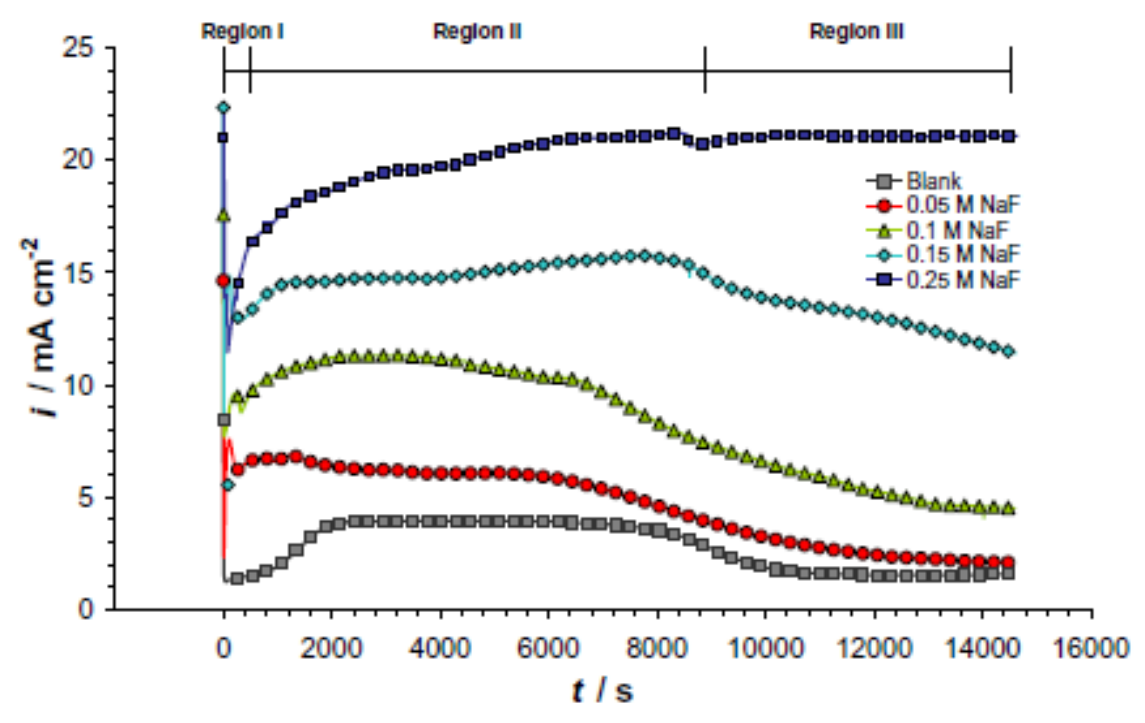

Figure 2 


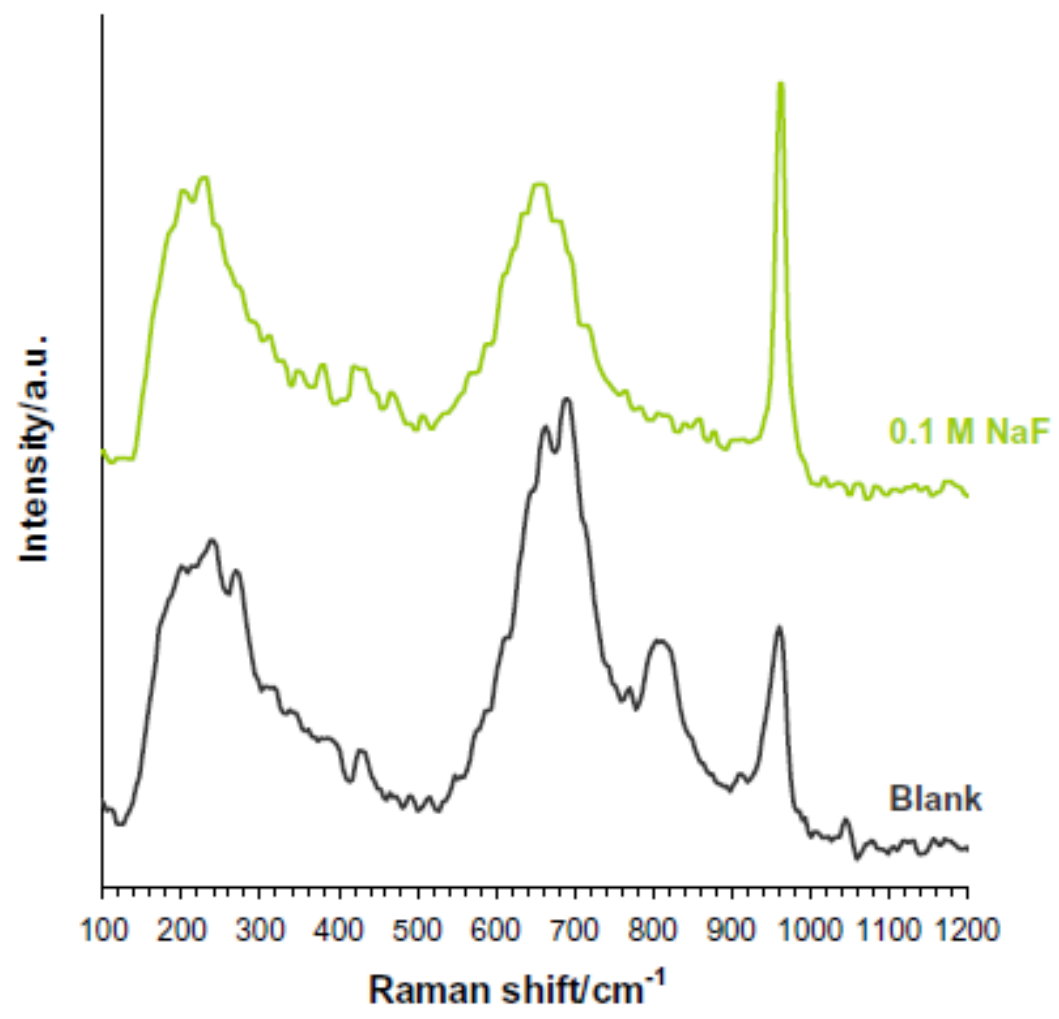

(a)

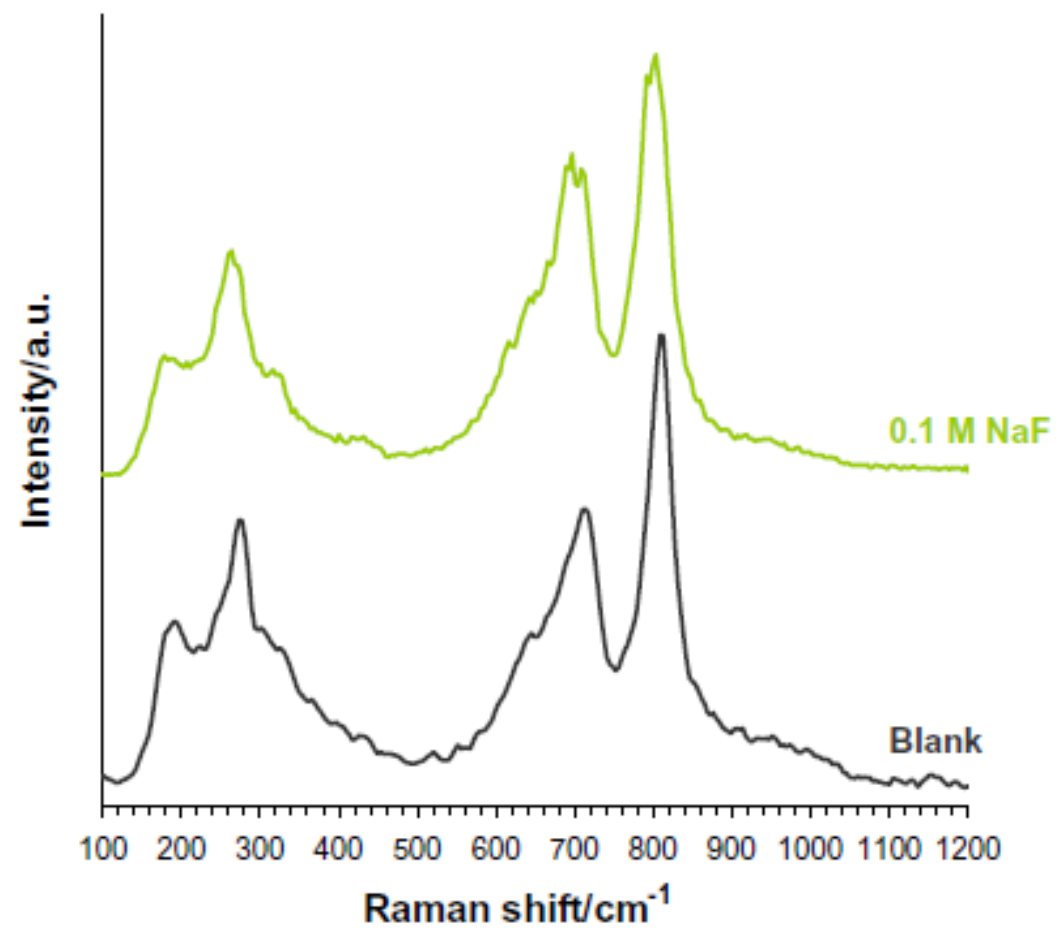

(b) 


\section{Figure 3}

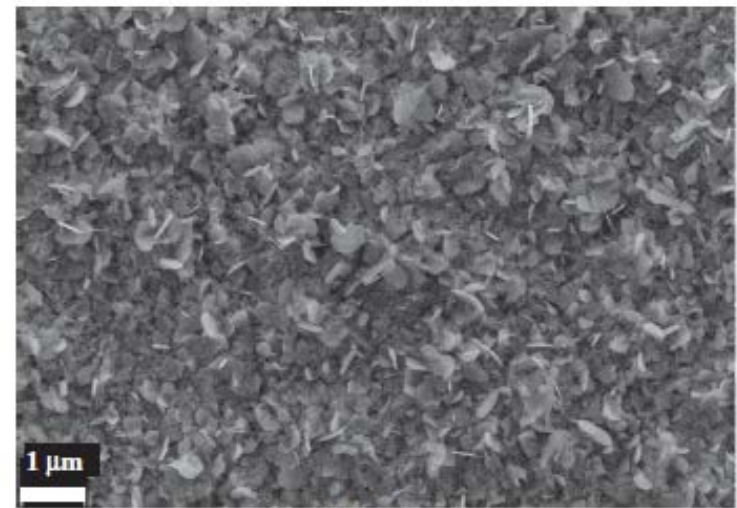

(a) Blank

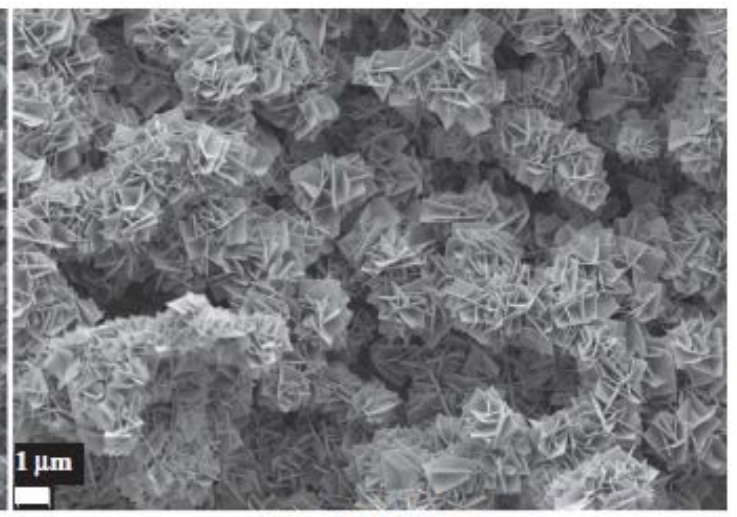

(b) $0.05 \mathrm{M} \mathrm{NaF}$

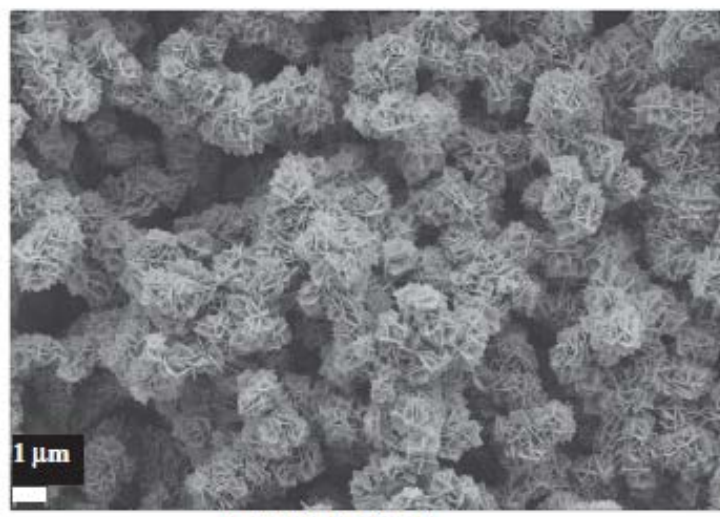

(c) $0.1 \mathrm{M} \mathrm{NaF}$

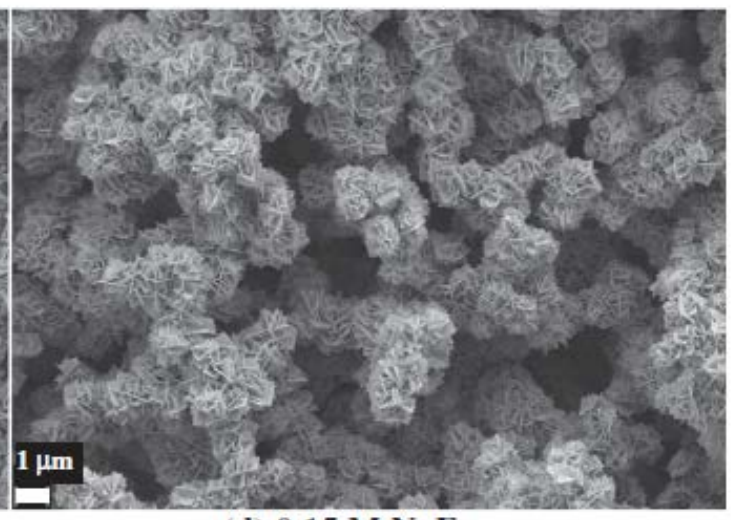

(d) $0.15 \mathrm{M} \mathrm{NaF}$

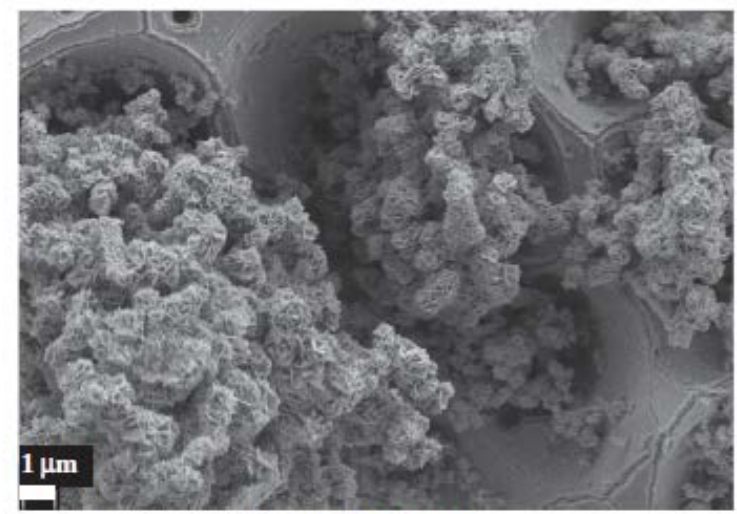

(e) $0.25 \mathrm{M} \mathrm{NaF}$ 


\section{Figure 4}

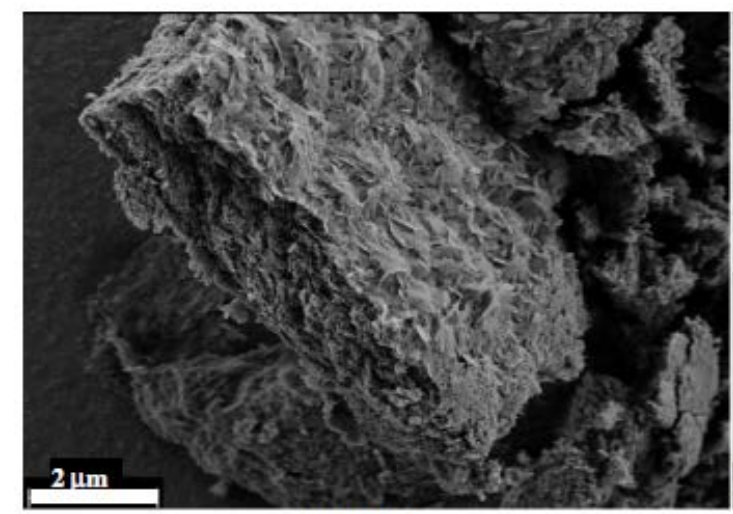

(a) Blank

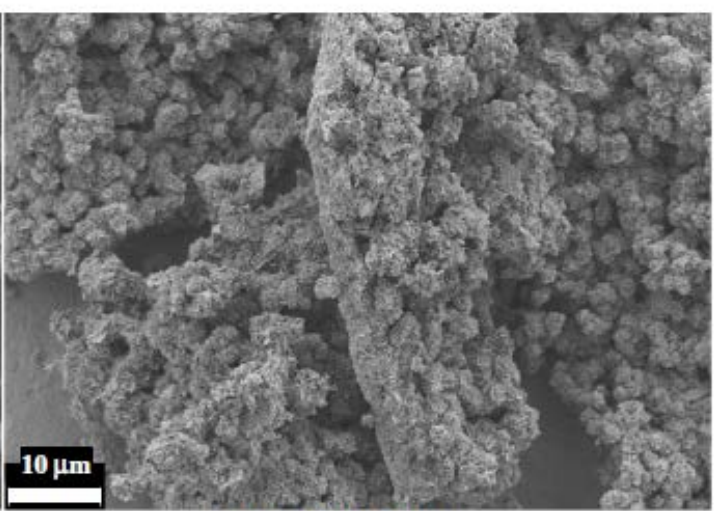

(b) $0.05 \mathrm{M} \mathrm{NaF}$

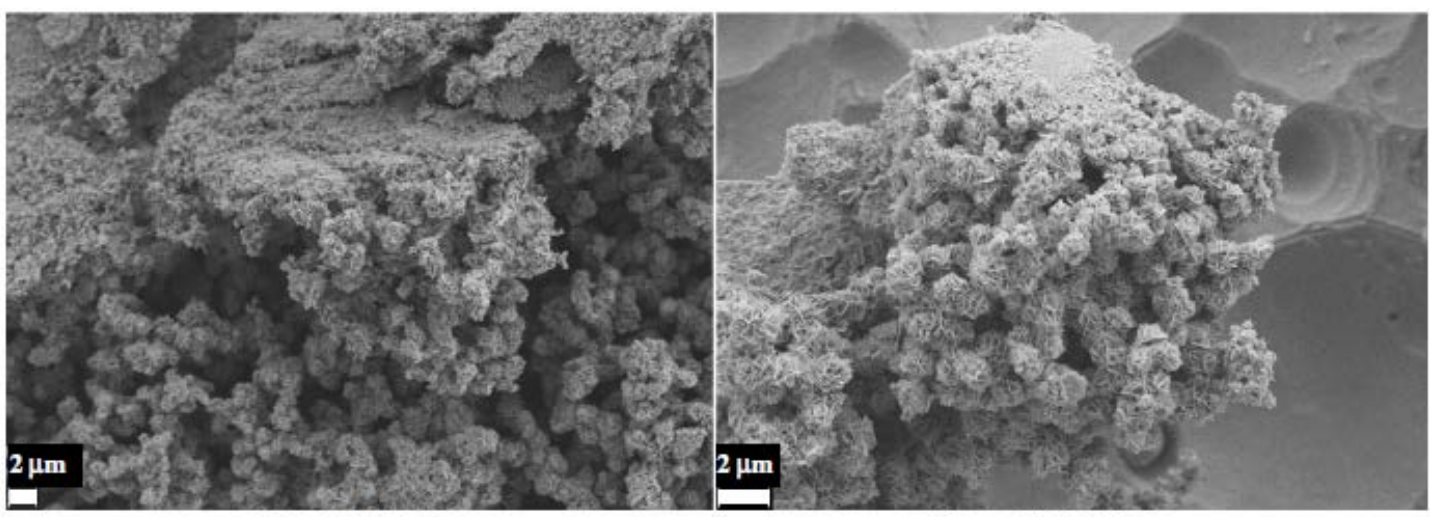

(c) $0.1 \mathrm{M} \mathrm{NaF}$

(d) $0.15 \mathrm{M} \mathrm{NaF}$

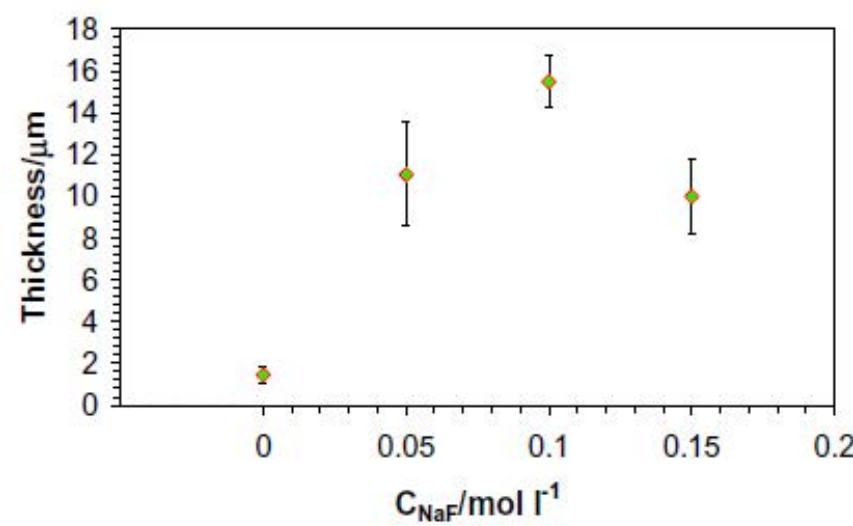

(e) 
Figure 5
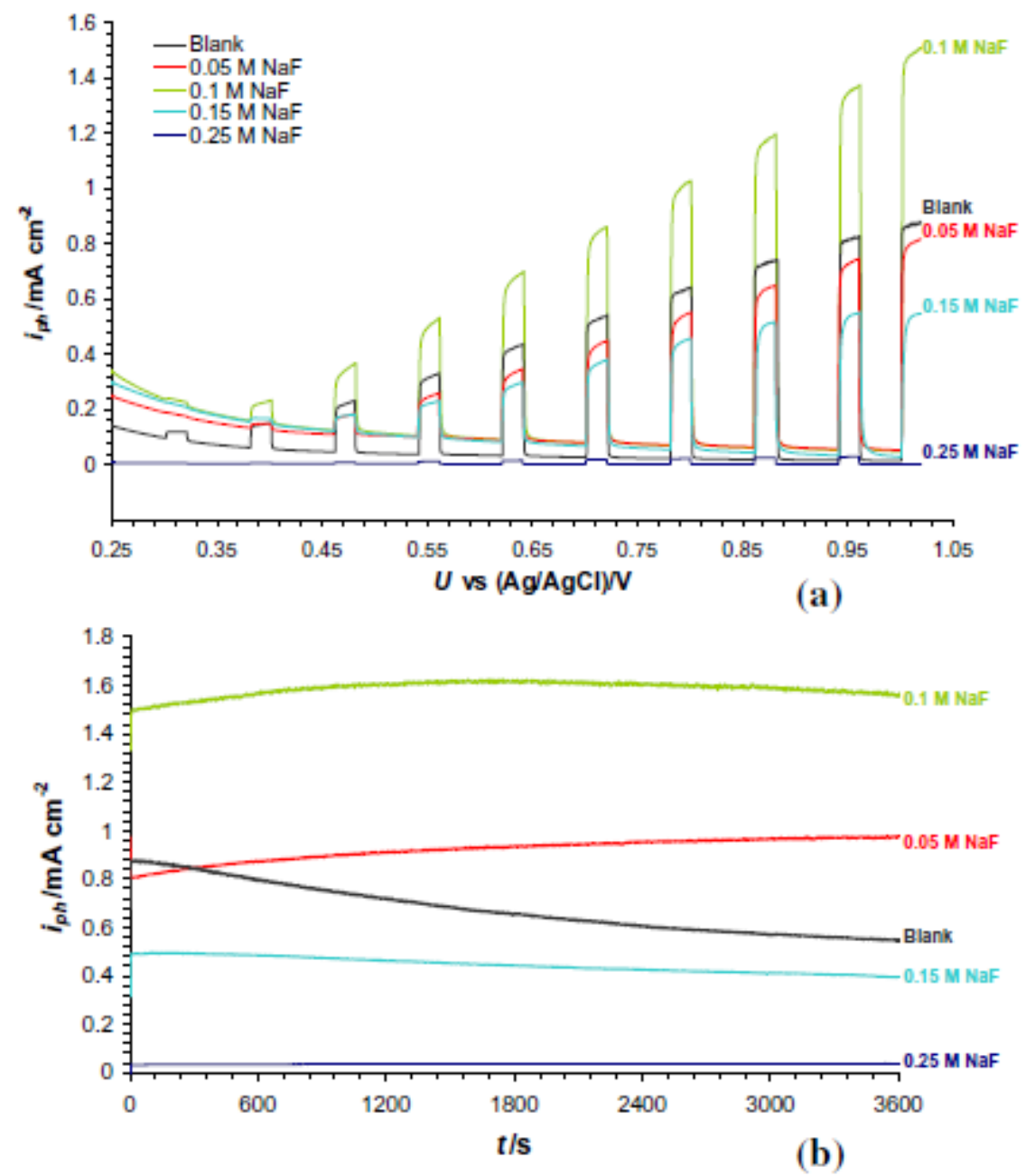

Figure 6

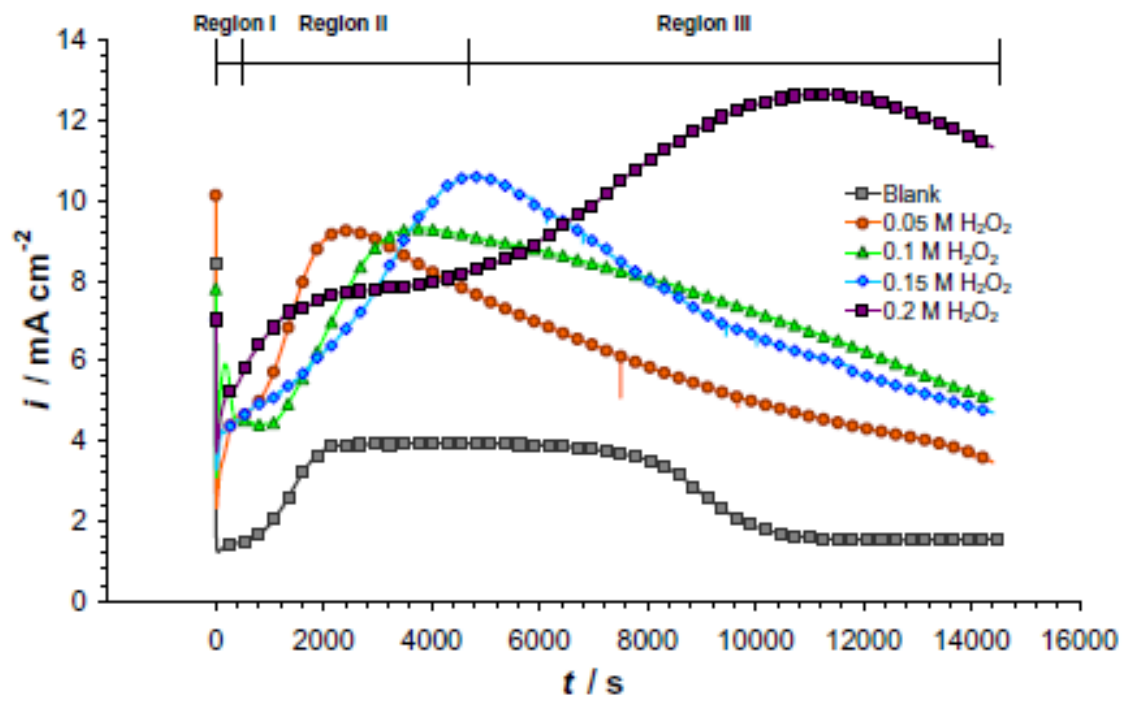


Figure 7
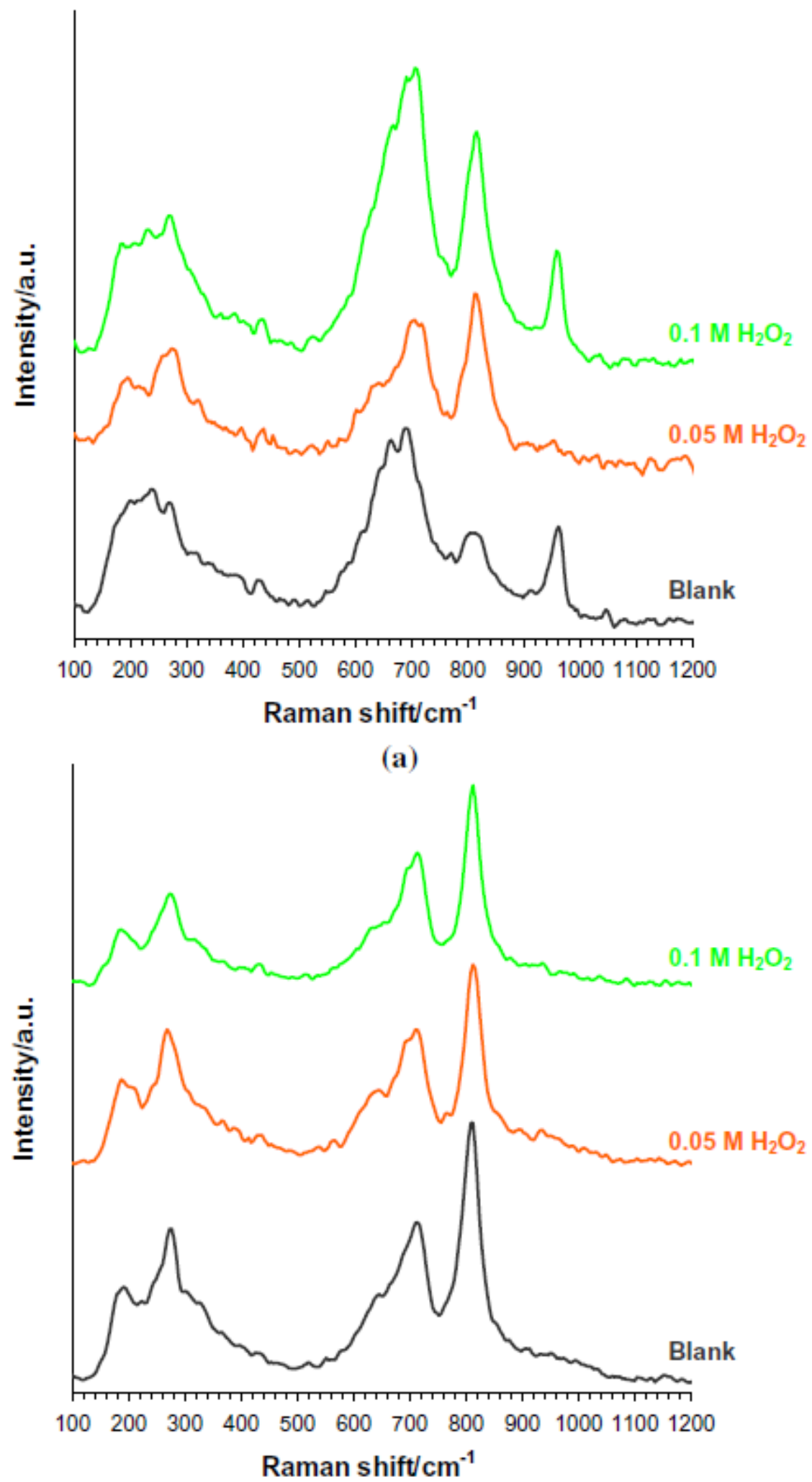

(b) 
Figure 8 


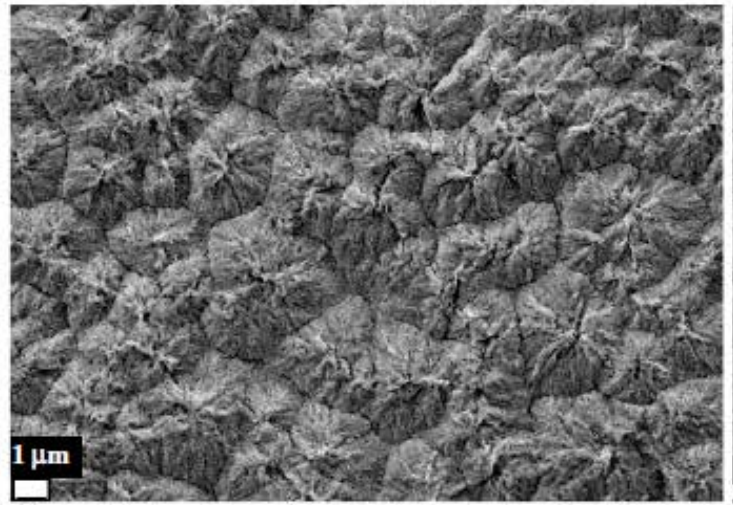

(a) $0.05 \mathrm{M} \mathrm{H}_{2} \mathrm{O}_{2}(5000 \mathrm{X})$

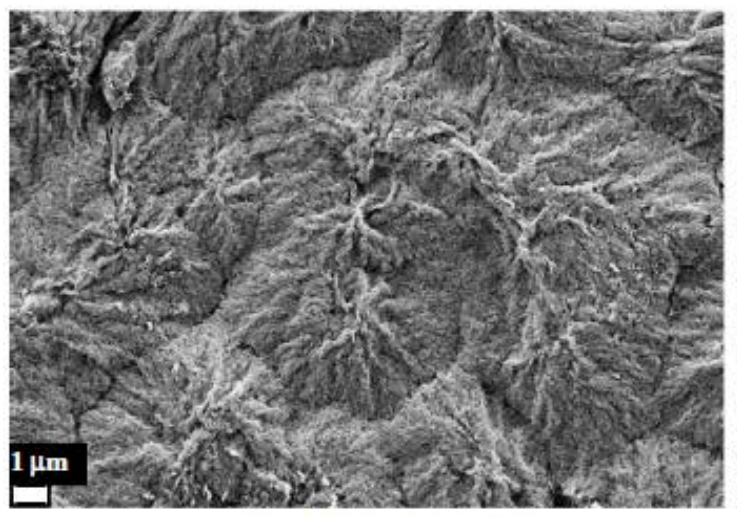

(c) $0.1 \mathrm{M} \mathrm{H}_{2} \mathrm{O}_{2}(5000 \mathrm{X})$

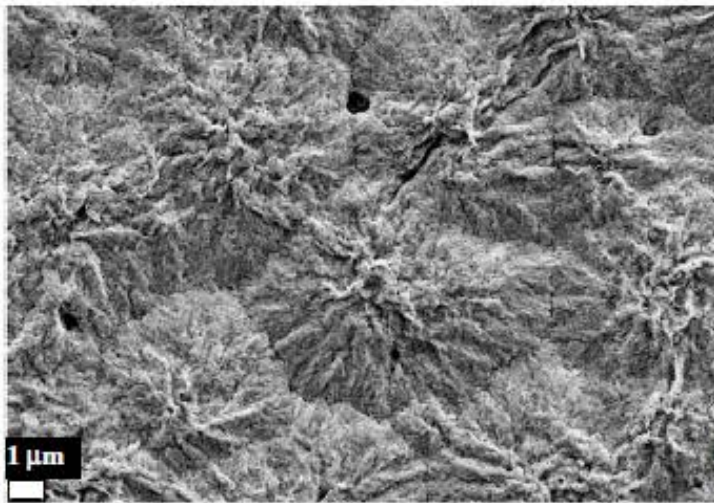

(e) $0.15 \mathrm{M} \mathrm{H}_{2} \mathrm{O}_{2}(5000 \mathrm{X})$

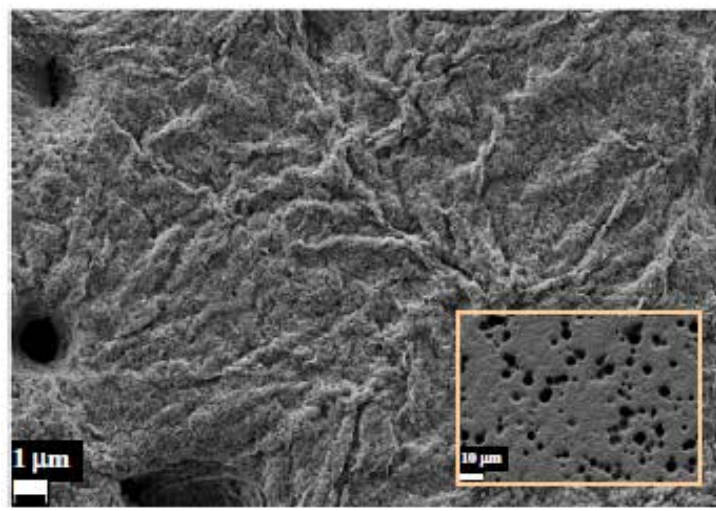

(g) $0.2 \mathrm{M} \mathrm{H}_{2} \mathrm{O}_{2}(5000 \mathrm{X})$

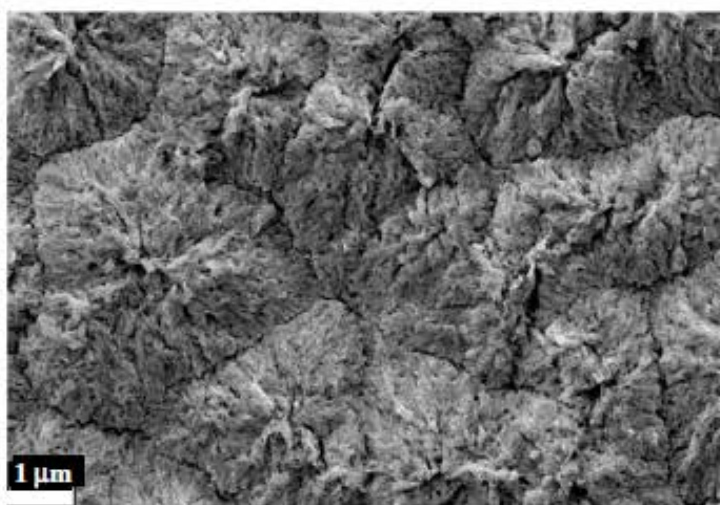

(b) $0.05 \mathrm{M} \mathrm{H}_{2} \mathrm{O}_{2}(10000 \mathrm{X})$

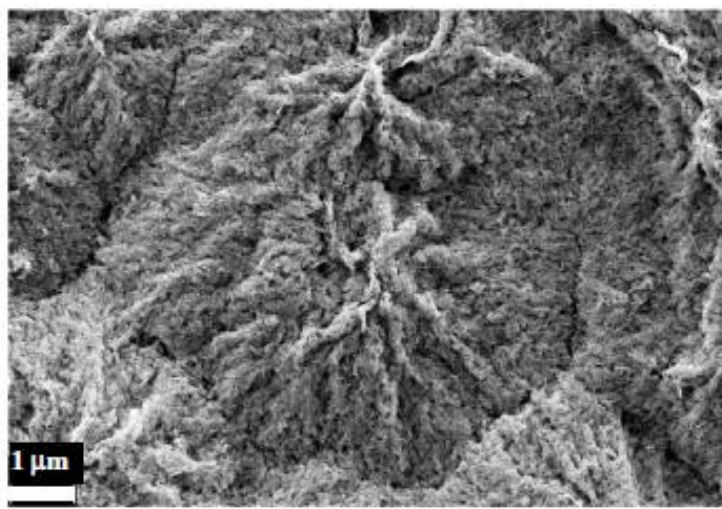

(d) $0.1 \mathrm{M} \mathrm{H}_{2} \mathrm{O}_{2}(10000 \mathrm{X})$

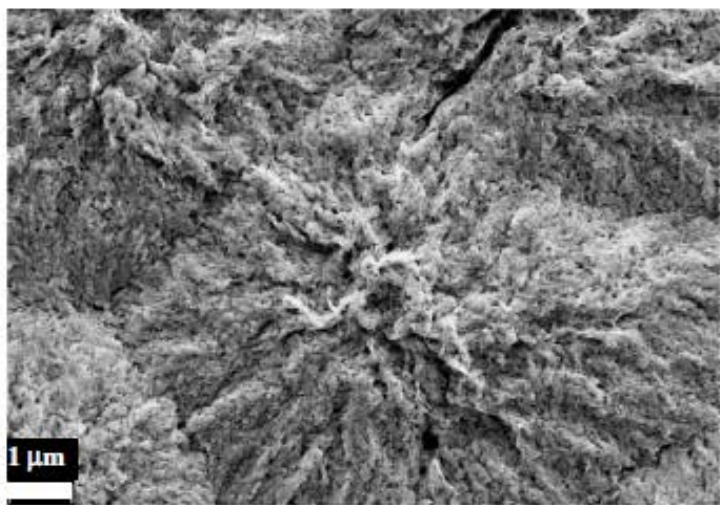

(f) $0.15 \mathrm{M} \mathrm{H}_{2} \mathrm{O}_{2}(10000 \mathrm{X})$

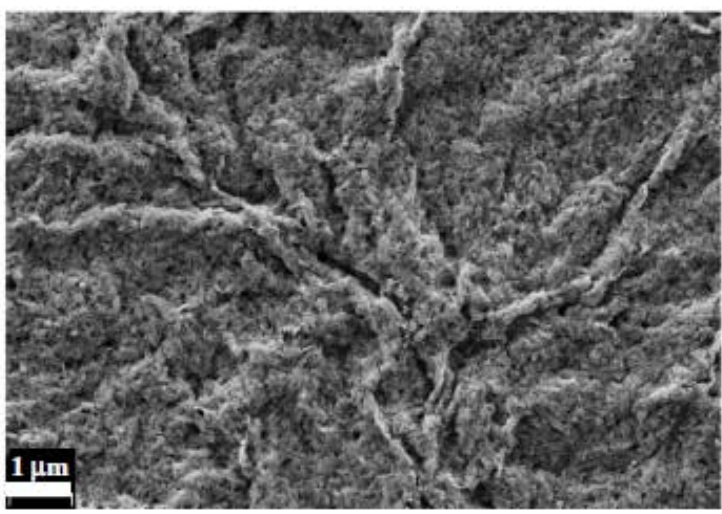

(h) $0.2 \mathrm{M} \mathrm{H}_{2} \mathrm{O}_{2}(5000 \mathrm{X})$ 


\section{Figure 9}

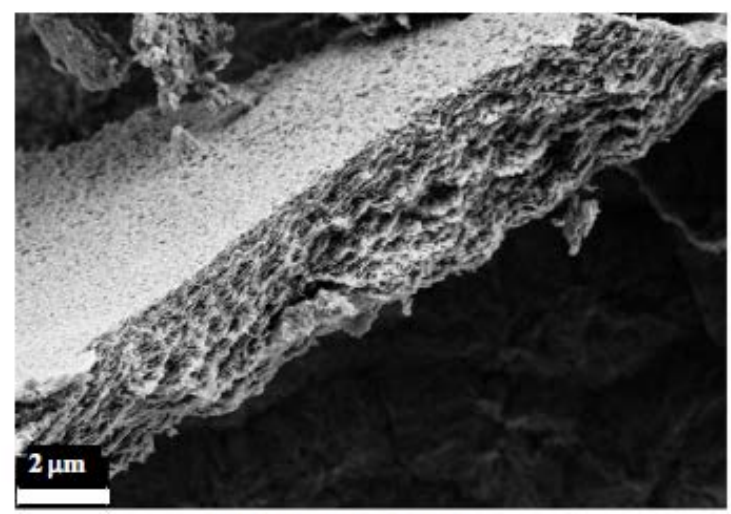

(a) $0.05 \mathrm{M} \mathrm{H}_{2} \mathrm{O}_{2}$

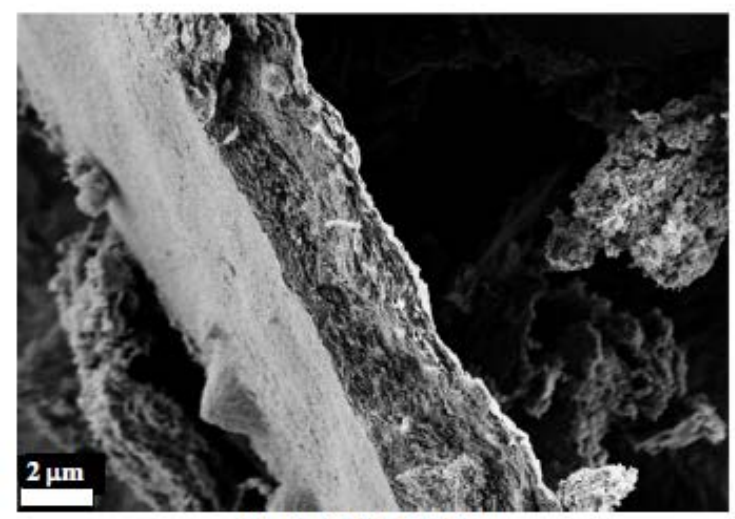

(c) $0.15 \mathrm{M} \mathrm{H}_{2} \mathrm{O}_{2}$

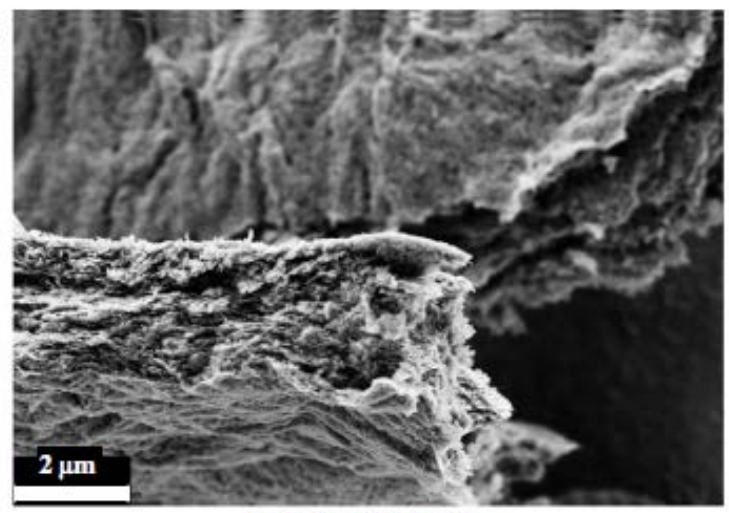

(b) $0.1 \mathrm{M} \mathrm{H}_{2} \mathrm{O}_{2}$

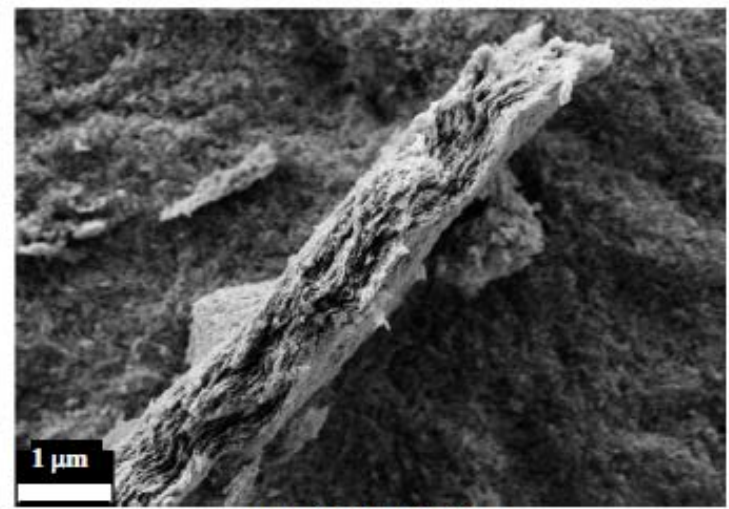

(d) $0.2 \mathrm{M} \mathrm{H}_{2} \mathrm{O}_{2}$

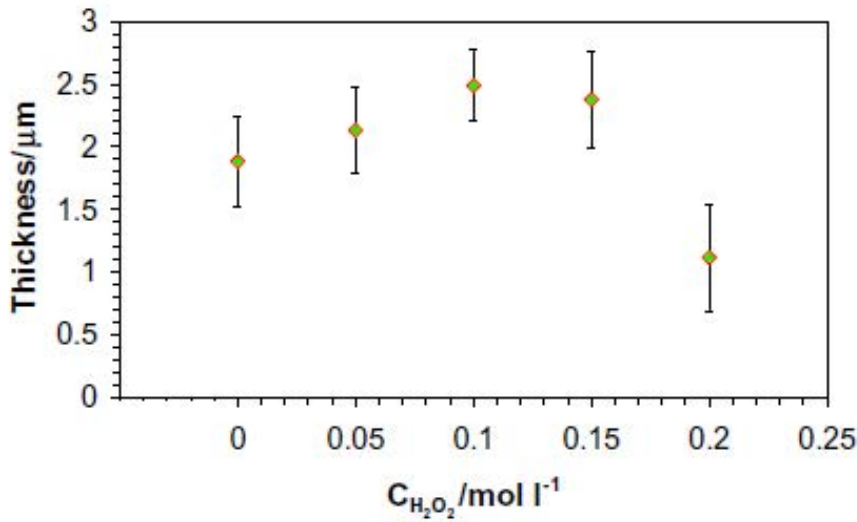

(e) 
Figure 10
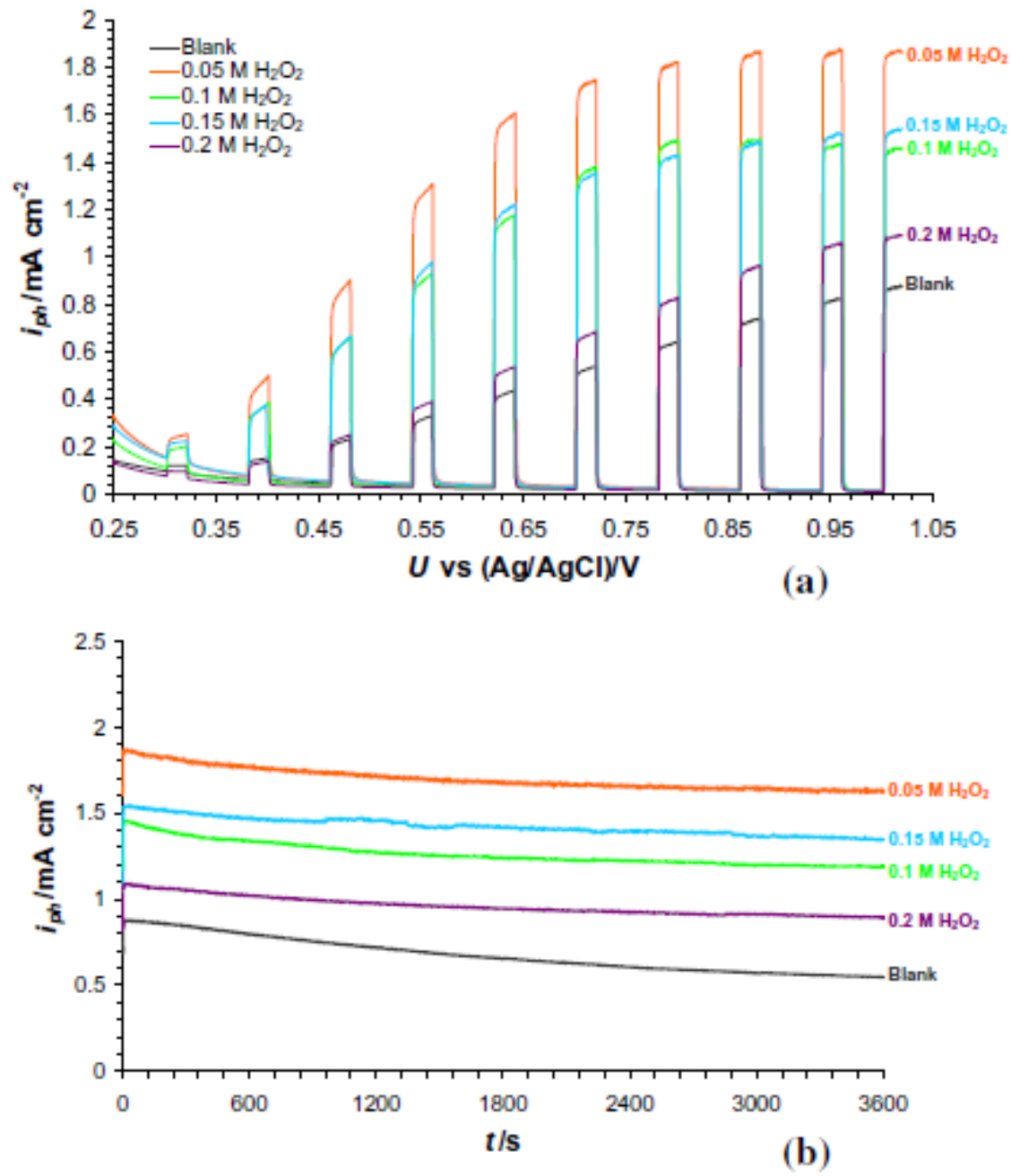